\title{
ETNOPOÉTICAS DEL UMBRAL: EL SIMBOLISMO DEL ARCO EN \\ LA CULTURA MAPUCHE WILLICHE Y SUS RECURRENCIAS EN LOS SISTEMAS COSMOVISIONARIOS ANDINOS
}

\author{
Rodrigo Moulian ${ }^{1}$ y Cristina Garrido ${ }^{2}$
}

\begin{abstract}
Resumen
Este artículo ofrece una aproximación al simbolismo del arco en el contexto etnográfico mapuche williche, donde este se encuentra como instrumento ritual con forma de dintel de arquitectura efímera, elaborado con ramas de especies vegetales y representando una puerta que comunica diversos niveles del universo. Para el análisis de este símbolo proponemos un desplazamiento de su lectura desde el particularismo cultural hacia un estudio comparativo en la perspectiva de un horizonte cultural andino. El resultado de ello es una ampliación en la compren-

sión de este motivo y la puesta en evidencia de correlaciones en los paradigmas cosmovisionarios centro y sur andinos. Al respecto, argumentamos que el correlato en los órdenes de representación, articulados en torno al simbolismo del arco, tiene un carácter histórico cultural, y

que sus recurrencias constituyen una manifestación cotradicional.
\end{abstract}

Palabras claves: representaciones - cotradición - andinidad - transculturalidad.

Abstract

This article offers an approach to the symbolism of the arc in the Mapuche Williche ethnographic context, where it is used as a ritual instrument shaped like a lintel of ephemeral architecture made with branches of plants, and represents a door between different levels of the universe.

For the analysis of this symbol we propose a shift in the reading from cultural particularism to a comparative study from the perspective of an Andean cultural horizon. The result is an expansion in the understanding of this subject and evidence of correlations in central and southern Andean worldview paradigms. In this regard, we argue that the correlation in the order of representation articulated around the symbolism of the arc has an historical and cultural character and its recurrences are a co-traditional expression.

Key words: representations - co-tradition - Andeanness transculturality.

Recibido: Julio 2014. Aceptado: Octubre 2015

1 Instituto de Comunicación Social de la Universidad Austral de Chile, Campus Isla Teja. Independencia 641, Valdivia, CHILE. Email: rmoulian@hotmail.com

2 Universidad Católica del Norte. Calle Gustavo Le Paige 380, San Pedro de Atacama, CHILE. Email: kasuegna@gmail.com
Aunque poco conocido y estudiado, el arco - instrumento ritual en forma de dintel de arquitectura efímera - es un elemento simbólico relevante en el sistema cosmovisionario mapuche williche. Su uso se registra en diversos espacios cúlticos, como las ceremonias de propiciación comunitarias denominadas lepün (ngillatun williche), los funerales o elewün y rituales de iniciación chamánicos denominados ngekuf rewen. En todos ellos, opera como puerta o umbral que conecta con otras dimensiones del universo, a través de las que transitan las entidades espirituales que se desea propiciar, invocar o ayudar a partir. El arco constituye aquí un nodo simbólico, un elemento en el que confluyen y se articulan diversos componentes de su sistema religioso, entre los que se encuentran representaciones cosmológicas, pneumatológicas, naturalistas y litúrgicas. Su función ritual compromete complejas tramas de sentido propias del trabajo modelizador de la cultura, que teje sus redes de un modo poiético, es decir, creativo e instaurador. La presencia de este mismo nodo simbólico en otros contextos culturales andinos deja en evidencia recurrencias sistemáticas en los órdenes cosmovisionarios de esta macro-región, cuyas variantes muestran un "aire de familia". Sus paralelismos sugieren la existencia de linajes cosmovisionarios cuyos órdenes de representación se encuentran vinculados, lo que actualiza el dictum levistraussiano de estudiar comparativamente los sistemas simbólicos de modo de revelar sus relaciones (Levi-Strauss 1984, 1986). En este artículo argumentaremos que estos vínculos no son solo estructurales sino también culturales, puesto que más allá de lo formal, se manifiestan en el plano de las representaciones. Los correlatos que ponen en evidencia esta relación no se expresan de modo inconsciente, en estratos de sentido subyacente que haya que develar (Rossi 1973), sino en correlaciones constatables en el sentido explícito que asumen las acciones simbólicas (ver Figura 1). 


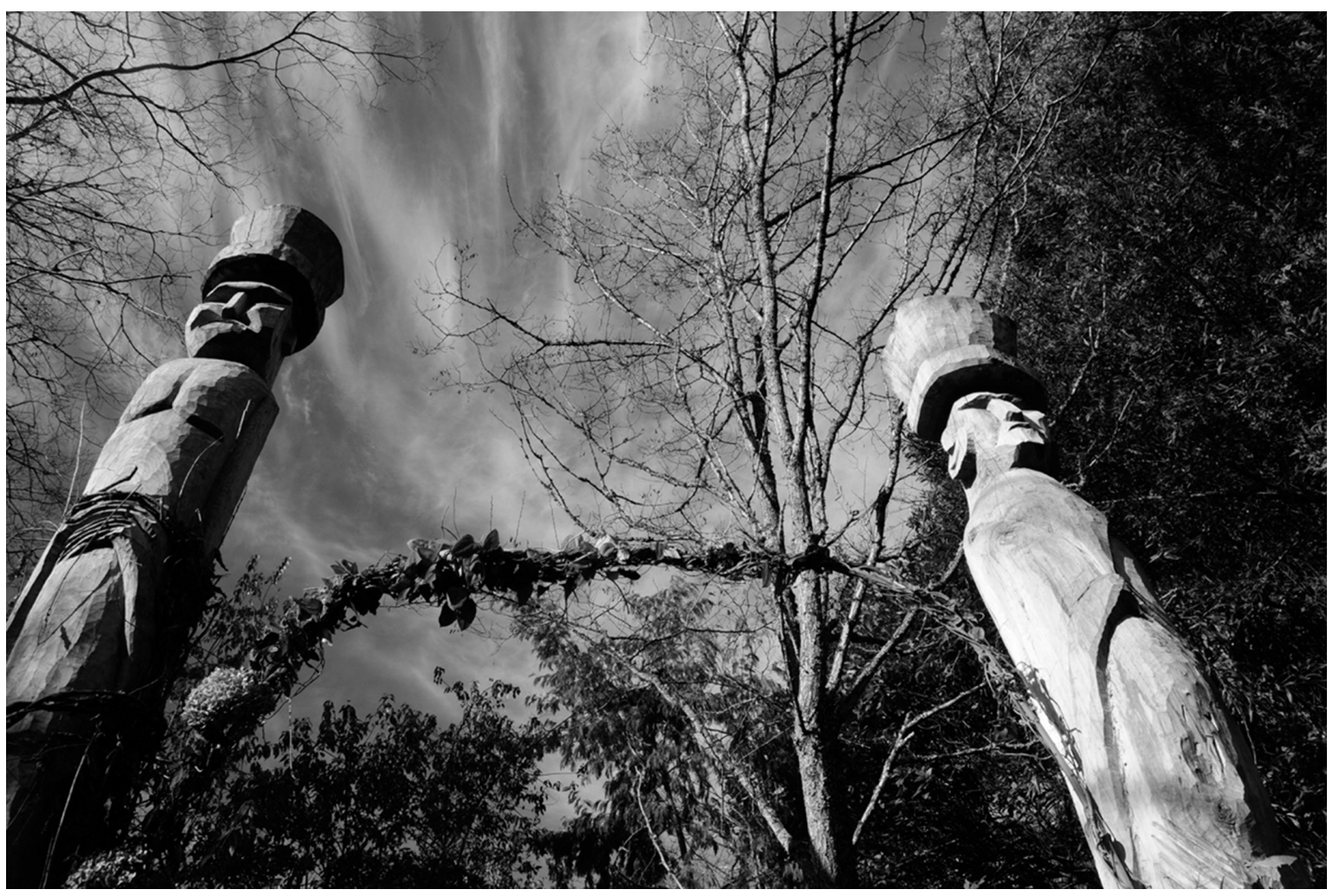

Figura 1. En el umbral del arco, che mamüll, figuras que representan espíritus ancestrales.

Como mostraremos, el registro arqueológico informa de la presencia del simbolismo del arco en el espacio central andino al menos desde el período Intermedio en las culturas moche y casma. Las fuentes etnohistóricas y el patrimonio iconográfico permiten constatar la continuidad del mismo y su importancia durante el incario. Los antecedentes etnográficos dan cuenta de su vigencia hasta el presente en las prácticas rituales de las comunidades atacameñas y aymaras. En estos diversos contextos, los componentes figurativos, simbólicos y funcionales del arco exponen un sistema de transformaciones en torno a un motivo constante: un pórtico cuyo umbral conecta las dimensiones del universo, el que se puede administrar simbólicamente. Este sistema de variantes en las representaciones en torno a este denominador común es lo que llamamos "etnopoéticas del umbral". Con esta expresión aludimos a las distintas concepciones y usos del simbolismo del arco en los diversos contextos culturales. Si bien en cada uno de ellos se encuentran particularidades y rasgos específicos diferenciadores, se advierten igualmente significativas coincidencias a nivel de los modelos y metamodelos cosmovisionarios implicados en el uso del arco. La pregunta que surge entonces es: ia qué se deben estos correlatos?, ¿se pueden explicar en términos naturalistas, expresan procesos históricos o una combinación de ambos? A nuestro entender, el nivel de complejidad y el carácter recurrente que presentan las correspondencias no permiten explicarlas solo en términos naturalistas. Ello nos lleva a plantear su comprensión en la perspectiva de la historia cultural de la macroárea donde se encuentran.

Para abordar este problema nuestro diseño de investigación se orienta a comparar los órdenes de representación expresados en las tramas simbólicas que se articulan en torno al motivo del arco, donde convergen distintos constructos que dan forma a modelos y metamodelos (modelos de modelos) del universo. A estos órdenes de representación, que configuran las imágenes de la realidad, los denominamos "paradigmas cosmovisionarios". Se trata, por lo tanto, de abordar los trenzados de sentido desplegados en torno a este motivo simbólico. El carácter nodal de la unidad de análisis (el simbolismo del arco), y su estudio en contextos rituales, permiten acceder a datos correspondientes a este nivel de elaboración semiótica. Con ello, intentamos 
evitar los riesgos de la descontextualización y deslindar el rango de aplicación de las teorías que explican en términos naturalistas las recurrencias simbólicas, como las de Jung (1994), Boyer (1994) o Levi-Strauss (1997). Sus capacidades explicativas alcanzan tanto el nivel de las formas significantes en la teoría de los arquetipos, como los principios sintácticos en el estructuralismo y ciertas unidades de contenido semánticos en la teoría cognitivista de la inferencia espontánea ${ }^{3}$. Lo relevante para nuestro caso de estudio son las correspondencias transculturales en el plegamiento de distintos órdenes de representación anudados en torno al simbolismo del arco. A nuestro entender, este correlato en las tramas simbólicas que expresan paradigmas cosmovisionarios constituye un indicador de "cotradición". Empleamos el término en el sentido que le da Lumbreras (1968-1969), para referir los rasgos culturales compartidos por culturas diferenciadas, a partir de los cuales se puede inferir la existencia de relaciones interculturales entre ellas. Dicho de otro modo, la noción de cotradición designa una tradición común arraigada en diversos entornos sociales, cuyos patrones concordantes presuponen un contacto o antecedentes culturales compartidos.

En tanto tal, este artículo retoma una discusión que tiene larga data, pero una posición relativamente marginal en la antropología sobre el pueblo mapuche, que aborda la influencia andina sobre su cultura. Al respecto distinguimos tres tesis, que podemos denominar "civilizatoria", "migratoria" y "de la circulación". La primera de ellas se expone originalmente en la obra de Barros Arana (1884), quien le asigna al incario un carácter civilizador de pueblos indígenas que habitaban nuestro país. La misma es asumida por Guevara (1911), autor que atribuye un origen incaico al sistema religioso cosmovisionario mapuche williche. En palabras de este (1911: 244): "el ngillatun fue, pues una ceremonia traída por los incas por cuanto en ella se manifiestan todos los caracteres esenciales del sacrificio en el culto

3 Para Jung, los arquetipos son formas simbólicas primordiales indefinidas en términos del contenido; el estructuralismo de LéviStrauss se ocupa de los principios de configuración de los sistemas culturales, no de sus tramas de sentido; el cognitivismo de Boyer postula la existencia de formas de inferencia intuitivas que pueden aplicarse al campo de los símbolos naturales, pero no a narrativas complejas. Estas teorías pueden explicar recurrencias en las dimensiones primarias de la semiótica, no de sus elaboraciones complejas. peruano: danzas, muerte de un animal, entierro de una parte de él, fuego sagrado". No obstante, los antecedentes etnohistóricos y arqueológicos no son consistentes con esta supuesta aculturación religiosa. Sobre esto, debe considerarse la brevedad del período de dominación del inca en el espacio centro y sur de Chile, cuyo inicio se ha estimado, a través de la datación arqueológica, en 1390 (Cornejo 2014), y cuyo término se produce con la llegada de Almagro en 1536. También ha de ponderarse su limitada extensión territorial en el espacio meridional, que alcanza hasta el Maule, y su política religiosa de respeto hacia los cultos locales. En contraste, la tesis migratoria se encuentra planteada inicialmente por Latcham (1924), para quien la cultura mapuche se origina en el movimiento de un pueblo proveniente de las pampas argentinas, al que denomina "moluche". En relación con el área andina, esta idea es retomada por Grebe (2002: 23), quien sostiene: "Aunque desconocemos el trazado específico de la ruta migratoria elegida por los mapuche al llegar al Nuevo Mundo, existen algunas evidencias que apoyarían su desplazamiento de norte a sur por la cordillera de Los Andes, utilizando ya sea la vía precordillerana/altiplánica o bien costera."

Desde mediados de la década de 1980, Grebe (1986, 1995-1996, 1996, 2002) desarrolla un programa de estudio comparativo de los sistemas simbólicos y modelos cognitivos aymara, atacameño y mapuche. En el marco de este, advierte el carácter andino de numerosos rasgos del sistema religioso cosmovisionario mapuche, como el culto a los espíritus de la naturaleza, el dualismo simbólico, la concepción del tiempo y del espacio. Al respecto, la autora se pregunta: "Es posible que los mapuche se hubiesen asentado en el territorio aymara de Tiawanaku con anterioridad a su radicación definitiva en el centro sur de Chile?" (Grebe 2002: 24). Sobre esto nos dice: "Sin ánimo especulativo, es posible considerar la posibilidad de un eventual contacto cultural temprano, quizás prolongado de los mapuche con la alta cultura andina aymara del Tiawanaku, ubicada en las proximidades del Lago Titicaca" (Grebe 2002: 23). No obstante, los datos sobre la antigüedad y continuidad de la ocupación del espacio centro y sur de Chile (Adán et al. 2004; Dillehay 2004) no avalan esta hipótesis migratoria. Más consistente con ellos resulta la tesis de la "movilidad giratoria" (Dillehay 1998a) o, como la llamamos nosotros, "de la circulación", que apunta a la profundidad histórica y continuidad del movimiento de grupos humanos, elementos simbólicos y 
materiales en el espacio centro y sur andino. Esta idea se encuentra expuesta en la obra del propio Dillehay (1990, 1998b, 2011), para quien la cultura mapuche muestra influencias andinas y amazónicas desplegadas en distintos momentos, considerando aportes preincaicos e incaicos. Los antecedentes que aquí exponemos son congruentes con esta tesis.

El estudio del simbolismo del arco en el mundo andino muestra relaciones de continuidad en los órdenes de representaciones de este espacio y aporta datos sobre la antigüedad de los mismos. Para poner esto en evidencia, desplegamos la información en dos momentos: una fase descriptiva e interpretativa del simbolismo del arco en distintos contextos culturales andinos y una fase comparativa y de discusión teórica, que constituye el corolario de la anterior. En el nivel descriptivo, la información que proveemos surge de tres orientaciones metodológicas cuyos resultados procuramos triangular: la etnografía (observación participante y entrevistas a informantes calificados), análisis iconográfico (lectura de imágenes y figuraciones en diversas materialidades) y el análisis documental de fuentes primarias y secundarias. Los datos etnográficos referentes al contexto cultural mapuche williche, que es nuestro punto de partida, se han producido en un ciclo de estudio sobre su religiosidad que abarca más de diez años de trabajo de campo (Moulian y Valdés 2001; Moulian 2005, 2012; Moulian et al. 2008). En tanto, la información sobre el contexto andino en el norte chileno se funda en diez años de trabajo de campo entre collas, atacameños y aymara (Garrido 1999, 2007; Cervantes, Garrido y Santander 2008; Garrido y Lemus 2013a, 2013b). Los antecedentes que cada uno de nosotros había abordado previamente desde una mirada particularista cultural y leído en términos émicos (Pike 1976), es decir, desde una lógica comprensiva, se despliegan ahora para trazar sus relaciones en una perspectiva comparativa.

Los principios procedimentales propuestos por Turner (1999) para el estudio de los símbolos guían nuestro trabajo interpretativo del motivo del arco. Conforme a lo planteado por este autor, complementamos el análisis exegético (la atribución de sentido de los propios actores) con el operacional (observación de los distintos contextos de uso de los símbolos) y el posicional (las diversas asociaciones de elementos simbólicos) en el marco de las prácticas religiosas. Para la identificación de las recu- rrencias transculturales realizamos un análisis semiótico comparativo de las tramas simbólicas y los órdenes de sentido que, en este caso, convergen en torno al motivo del arco. Ello supone la búsqueda de paralelismos en los niveles sintáctico, semántico y pragmático de la semiosis (Morris 1985) y el análisis de sus articulaciones. Es decir, correlaciones que se despliegan desde el nivel formal comprenden el contenido y los usos sociales. Nuestra investigación opera implícitamente con el modelo triádico de la semiosis (Peirce 1965, 1974), reivindicado para la antropología por autores como Parmentier (1994) y Preucel y Bauer (2001). No obstante, no empleamos explícitamente su terminología por la falta de estabilidad conceptual de la misma (Marty 1997) y poco de arraigo en nuestro espacio académico. Nuestra posición, en este sentido, es ecléctica, pues preferimos el uso de términos provenientes de la tradición estructuralista, como las nociones de significante y significado (Saussure 1986) para aludir a los componentes del plano sintáctico y semántico de la semiosis. En tanto, empleamos la noción de usos sociales para aludir al nivel pragmático. No obstante, en este artículo optamos por reducir al mínimo el uso del metalenguaje semiótico para concentrarnos en la exposición de los antecedentes empíricos de nuestro objeto de estudio. No ofrecemos aquí, por lo mismo, un análisis semiótico formalizado del simbolismo del arco. Nuestro trabajo se ha orientado por el método semiótico para la descripción de los elementos del plano de la expresión, el contenido (Eco 1980) y de los usos sociales de nuestra unidad de análisis en diversos contextos culturales. Sin embargo, preferimos presentar y comparar estos datos en términos de prácticas y patrones culturales para evitar que el metalenguaje teórico distraiga la atención sobre la fenomenología de nuestro objeto de estudio.

\section{Relmu, una puerta abierta al cielo}

Las congregaciones rituales mapuche williche del área lelfunche (gente de los llanos) de las comunas de Lago Ranco y Río Bueno, Región de Los Ríos, emplean en sus rogativas comunitarias rewe en forma de arco. Etimológicamente este término del mapudungun se compone de las raíces "re", que significa "puro" o "auténtico", y "we", que designa "lugar" e "instrumento". El rewe es un símbolo religioso empleado como elemento mediador de la comunicación entre los seres humanos, las deidades y espíritus ancestrales. La forma que adopta varía según los contextos rituales donde aparece y según las zonas etnográficas. Las machi o cha- 


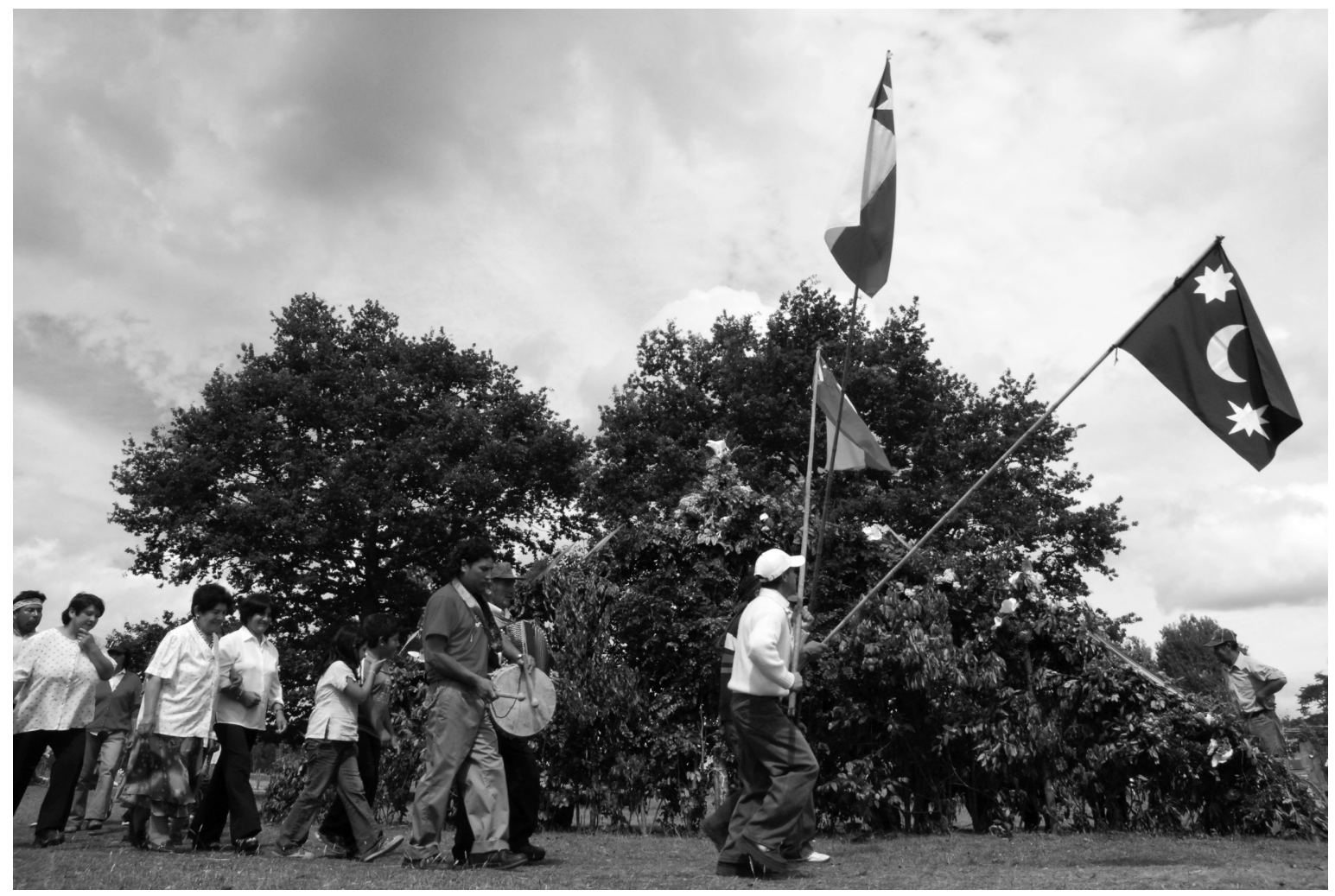

Figura 2. Relmu, rewe de arco en la comunidad de Maihue Carimallín.

manes mapuche suelen emplear un praprawe, tronco de canelo con peldaños labrados en forma de escalera. Algunas comunidades emplean chemamüll, figuras antropomorfas de madera que representan a los espíritus ancestrales. En otras, este se compone habitualmente de la asociación de diversas especies vegetales: canelo, laurel, coligüe, maqui. Su figuración en forma de arco constituye una variante localizada del mismo, que encontramos vigente en las comunidades de Maihue Carimallín, Nolguehue (ubicadas en la comuna de Río Bueno) y Tringlo (situada en la comuna de Lago Ranco). Aquí, el rewe se confecciona con varas de avellano, especie seleccionada por la flexibilidad de su madera. Estas son cubiertas con flores y dispuestas en el centro del ngillatue o campo de ceremonias, de manera de levantar un portal orientado en dirección este-oeste. En torno a este elemento se desarrollarán las principales acciones rituales propias del lepün o ngillatun williche, consistentes en oraciones, sacrificio de animales y entrega de ofrendas, bendición de los alimentos y bailes ceremoniales.

Según los miembros de las congregaciones rituales, el rewe de arco representa al arcoíris, que en mapudungun se de- nomina relmu. En términos figurativos y operacionales, este elemento simboliza una puerta interdimensional, a través de la cual se puede transitar por distintos planos de realidad. En la cosmovisión mapuche, el universo se compone básicamente de tres estratos que se organizan verticalmente y se encuentran articulados de manera circular: el Wenu Mapu, mundo de arriba (también asociado al Puel Mapu u oriente); Nag Mapu, mundo intermedio, donde habita el hombre; y el Minche Mapu, mundo de abajo (vinculado al Lafken Mapu u occidente) ${ }^{4}$. Al tender el arco, los miembros de las congregaciones rituales establecen un puente que permite el desplazamiento de las entidades espirituales entre estos niveles circularmente entrelazados. Por lo mismo, los espíritus tutelares de las comunidades de Maihue (Kintuante) y Nolguehue (Juanico) se encuentran representados simbólicamente bajo este arcoíris vegetal,

4 La investigación etnográfica registra esquemas más complejos de este etnomodelo, donde se identifican siete o más niveles del universo, los que resultan de la estratificación interna de este esquema tripartito básico (Grebe, Pacheco y Segura 1972; Dillehay 1990). 
en la forma significante (Saussure 1986) de ramas de laurel traídas desde los espacios naturales que se consideran sus moradas. Estas ramas son alimentadas con chicha de trigo y sangre de los animales sacrificados. De acuerdo a los participantes, al momento de levantar el arco se puede percibir la llegada de los antepasados en torno al rewe, que se manifiesta en forma de brisa proveniente desde el oeste o Lafken Mapu (ver Figura 2).

La cultura mapuche concibe el paisaje como un entorno espiritualizado y abierto a la interacción entre los diversos niveles del universo. La topografía es aquí reflejo de la cosmología, en tanto se encuentra revestida de múltiples puntos de conexión entre estos estratos que configuran el mundo. El término konünwenu, por ejemplo, significa en mapudungun "entrada al cielo" y refiere a diversos espacios naturales que se consideran vías de acceso hacia el mundo de arriba. Dada la articulación circular de los diversos niveles del cosmos, es posible acceder al plano superior por vía subterránea. Así, cuevas, ojos de agua, cráteres volcánicos, troncos huecos, zonas pantanosas conocidas como "hualves" se inscriben como potenciales ejemplares de esta categoría. En las comunidades de Maihue y Nolguehue vemos la vigencia de estas representaciones. Allí los espíritus tutelares, que sirven de mediadores ante Dios, son sujetos abducidos por espacios poderosos, que en este caso corresponden a cuevas, donde hoy se encuentran emplazados. Es lo que sucede con Juanico en Nolguehue y Kintuante en Maihue, a quienes hoy se rinde culto como Ngen Mapu, considerados "dueños del territorio". Se trata de personas cuya desaparición se explica por su acceso a unos puntos de entrada en la tierra que conducen hacia al mundo de arriba. El término con que se designa en mapudungun a estos lugares es renü, que literalmente significa "capturado por lo puro". El proceso de ancestralización, es decir, de transformación de las personas en espíritus ancestrales, se encuentra asociado al acceso a estos espacios liminares, que conducen al Wenu Mapu y tienen un carácter trascendente, pero al encontrarse emplazados en el Nag Mapu asumen una presencia inmanente que permite el acceso de los creyentes a ellos. La geografía sagrada mapuche se presenta porosa, y su geología, intersticial. Dado a que funcionan como puertas interdimensionales, sus hitos se transforman en lugares de culto y puntos de peregrinaje.

Fenómenos meteorológicos como el rayo y el arcoíris, que conectan la atmósfera y la tierra, son concebidos como puentes entre los estratos del mundo mapuche. Por ello, además de vínculos etimológicos, las nociones de rewe, relmu y renü presentan connotaciones que correlacionan sus funciones cosmovisionarias y rituales. En la perspectiva de la semiótica estructuralista (Barthes 1972; Saussure 1986), estas se inscriben dentro de un mismo campo paradigmático. Ellas refieren a elementos numinosos (Otto 2001), es decir, revestidos de poder y misterio, que caracteriza a lo sagrado, por lo que demandan una actitud de cuidado y respeto. Así se advierte en el sistema cúltico de las comunidades de Maihue y Nolguehue, donde el lepün se inicia con el peregrinaje de los kamaskos, como se denominan los miembros de las congregaciones rituales, hasta los renü que sirven de morada de los espíritus tutelares o Ngen Mapu. Hasta allí concurre una delegación encabezada por las autoridades rituales para invocar y propiciar la participación de los Ngen en la rogativa. Los kamaskos recogen en el entorno del renü una rama o gancho de laurel - denominado en Maihue "el caballito", porque en él "va montado el espíritu"-, la que llevarán hasta el arco sagrado que sirve de rewe. El circuito ceremonial va desde el renü al rewe, que en estas comunidades adopta la forma de relmu. El primero es una puerta interdimensional donde habita el Ngen Mapu, el segundo un instrumento destinado a permitir el encuentro entre la congregación, la deidad y los espíritus ancestrales. En este caso, la forma y la función simbólica del rewe se complementan, puesto que el arcoíris se concibe como un puente tendido al cielo, bajo cuyo umbral se conectan las distintas zonas de la geografía sagrada.

La especificidad funcional de este motivo simbólico queda en evidencia en un nütram recogido por nosotros en Chanchán, costa de Valdivia, que versa sobre un arcoíris a través del cual se desplazan las almas. El relato informa la repentina e inesperada desaparición de una anciana mapuche, que una mañana sale de su casa ataviada con todas sus joyas y no regresa más. La comunidad se organiza para buscarla sin resultados. Finalmente deciden ir hasta un trayenko, que tiene fama de ser un "lugar encantado", donde se dice vive el espíritu de un toro negro. Allí la encuentran sin vida, sentada en una roca y con los pies en el agua, mirando la caída sobre la que se levanta el arcoíris, a través del cual se ha producido el "rapto" de su alma. En Calafquén nos señalaron que la visión del arco del cielo es presagio de muerte, por lo que su imagen adopta un carácter ambivalente. A la inversa, su uso como instrumento simbólico contribuye a la partida de las almas a la otra 
vida. Así lo vimos en el funeral del ñizol longko Leonardo Cuante Loncoman el año 2008, en cuya tumba se puso un arco sobre el chemamüll, recuperando tradición ancestral vigente antiguamente en Lago Ranco y Río Bueno. De acuerdo a testimonios recogidos en las comunidades de $\mathrm{Pi}$ triuco y Nolguehue, en el pasado se acostumbraba levantar arcos sobre las tumbas de los miembros de las congregaciones rituales mapuche, conocidos como kamaskos.

Un dato etnolingüístico relevante es que esta voz, que designa a quienes organizan las rogativas y mantienen vivas las creencias ancestrales, no es de origen mapuche. Prueba de ello es que no se encuentra consignada en los diccionarios del mapudungun. El término es de origen quechua. En esta lengua, camasca (/kamaska/) designa a quien recibe el soplo vital de un "camac" o espíritu vitalizante particular, con quien mantiene un vínculo ritual e identitario (Taylor 2000). Esto es exactamente lo que sucede entre los kamaskos de Lago Ranco y Río Bueno que rinden culto a espíritus tutelares locales y levantan periódicamente arcos en ceremonias comunitarias, donde estos espíritus sirven como mediadores para comunicarse con el wenumapu (Moulian y Catrileo 2013, Moulian y Espinoza 2014) (ver Figura 3).

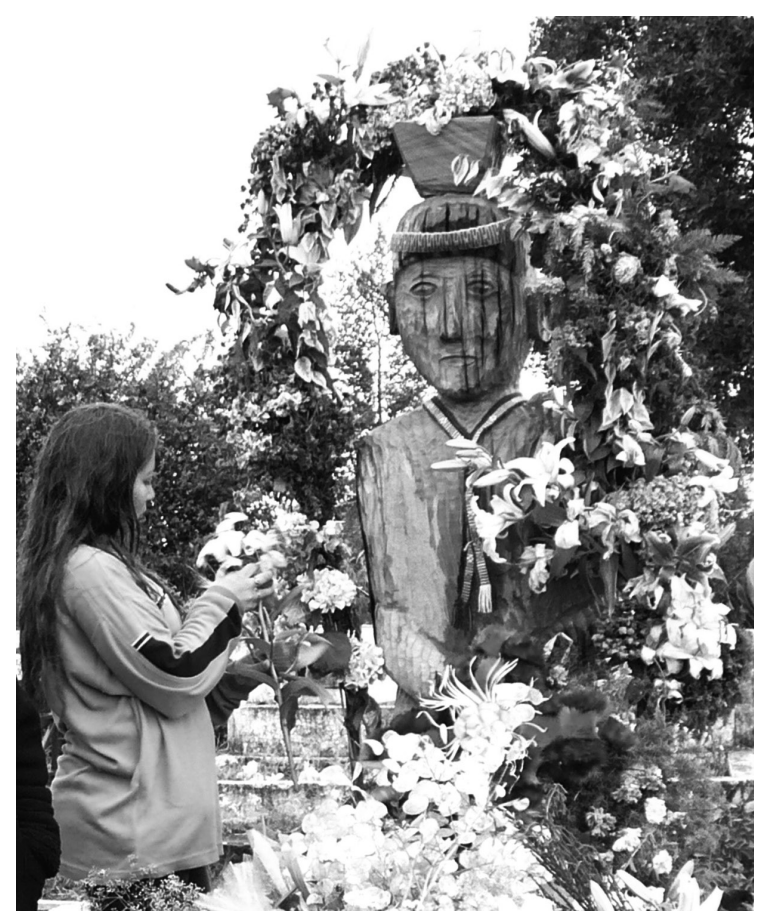

Figura 3. Funeral de Longko Leonardo Cuante Loncoman, en Pitriuco, Lago Ranco. Fotografía: Nelson Rodríguez.

\section{Nodo simbólico}

En tanto vía de tránsito espiritual, el simbolismo del arco encuentra un lugar destacado en los rituales chamánicos mapuche, donde se lo emplea como una forma de inducir o señalar el kuymun, acceso o trance místico. Flury (1944) describe su uso en las ceremonias de iniciación de los machi, en el territorio williche argentino, en un ritual que denomina ñecufrehuen (sacudir el rewe) o rehuetun. De acuerdo a este autor, el aspirante es colocado bajo un arco portátil compuesto de ramas y flores. Su maestro se sitúa frente a este, entonando cánticos, acompañado de su kultrung, mientras dos jóvenes asistentes, denominadas calfumalen (doncellas azules), mecen el rewe sobre el aspirante. Según Augusta (1916), en la zona de Panguipulli los machi acostumbraban a levantar rewe en forma de arcos hechos de palqui sobre los enfermos. De este modo se busca propiciar la acción de los espíritus auxiliares del machi sobre los pacientes.

Su función vaso comunicante es ratificada por Bacigalupo (2007: 55-56): "algunas machi ponen un llang llang —un arco hecho de boqui en forma de arcoíris (relmu) - sobre su rewe para representar su íntima conexión con los espíritus del bosque, especialmente con los espíritus dueños de la naturaleza que encuentran en sus visiones. Los arcoíris son las manifestaciones visuales del poder que emana del bosque de boqui". De allí las alusiones al arcoíris en las canciones de machi: "Estoy de pié y firme sobre el arco iris de los canelos de mi rehwe / estoy de pié y firme sobre el arco iris de los laureles de mi rehwe / estoy de pie y firme sobre la yerta mata que adorna mi rehwe. / Que hermosos se ve el arco iris de las matas de canelo que adornan mi rehwe. / Se mueve con movimientos rítmicos el arco iris de las matas de laureles que adornan mi rehwe, cuando los sacude desde la altura, desde el azul del cielo" (Alonqueo 1979: 99). Esta asociación entre los ganchos de plantas nativas y el arcoíris expresa su equivalencia funcional como puente de comunicación entre los estratos del mundo mapuche. Enraizadas en la Minche Mapu, las especies vegetales se proyectan desde el Nag Mapu hacia el Wenu Mapu. Por ello, las ramas también se emplean como materialidad significante del vínculo sagrado, que constituye al rewe.

El análisis del uso del arco en el contexto ritual pone en evidencia su funcionamiento como nodo simbólico, es decir, punto de articulación en que convergen diversos 
campos de representaciones propias del orden cosmovisionario. Como hemos señalado, el arco es un espacio de interconexión entre los niveles del cosmos, por el que transitan las entidades espirituales y a través del que es posible acceder o comunicarse con ellas. Su funcionamiento presupone y activa conocimientos correspondientes a: a) los elementos de la naturaleza y sus propiedades conectivas; b) los estratos que constituyen al mundo, sus relaciones y los seres que habitan en ellos; c) las entidades espirituales, sus manifestaciones y las relaciones que mantienen con los seres humanos; d) las formas del culto a las deidades y espíritus.

Así, el emplazamiento del rewe en los campos de rogativas se realiza en función de los patrones de disposición espacial que organizan su concepción del universo. El diseño de las canchas rituales lleva inscrito este cosmograma. En el caso de las comunidades williche de Maihue, Nolguehue y Tringlo, la configuración del rewe en forma de arco hace más explícito este juego de coordenadas. El trazado de la parábola se proyecta de norte a sur, de modo que el área comprendida bajo ella señala en el eje horizontal un corredor en línea este-oeste (Puelmapu-Lafkenmapu), con predominio y direccionalidad hacia el primero de estos puntos cardinales, desde donde se produce la salida del sol. Su despliegue en el plano vertical vincula el Wenu Mapu, el Nag Mapu y el Minche Mapu.

En la perspectiva mapuche, el trazado del sol en el curso diurno muestra la articulación circular de estos dos ejes (horizontal y vertical) en un movimiento que se denomina wallongtun, correspondiente al giro cósmico, que va de derecha a izquierda y al que se le atribuye un carácter integrador. Este se reproduce en el purun o baile y en el awün, desplazamiento circular a caballo en torno al espacio ritual. Para la cultura mapuche, el levante (Tripaiantu) y el poniente (Konünantu) son puntos de acceso a los mundos de arriba y de abajo, que se encuentran interconectados y que se asocian de forma simbólica a la vida y la muerte, respectivamente. Los espacios supraterrestre y subterráneo se consideran como parte de un continuo cuyos vínculos se enfatizan en la acción ritual. Por lo mismo, para alimentar a los espíritus de los antepasados, que se sitúan en el Wenu Mapu (mundo de arriba), se riega con sangre un hoyo cavado al lado del rewe, para que fluya hacia las entrañas de la tierra (mundo de abajo). El rewe es punto de confluencia de los planos y entidades que conforman el universo. En él se hacen presentes no solo los espíritus tutelares de las comunidades, sino también las almas de las personas que antiguamente participaron de las ceremonias.

En las rogativas de la comuna de San Juan de la Costa, los arcos se emplean como puertas de entrada y salida del noillatuwe, situadas al norte y sur, respectivamente. El campo sagrado cuenta, no obstante, con un tercer ejemplar denominado "arco de la interrogación", que opera como espacio de mediación. Desde allí, las congregaciones enuncian en forma colectiva una oración formalizada a las deidades y espíritus que conforman el panteón williche:

"Leuktetumayen Chau Trokin (Acuérdate de nosotros padre justiciero) / Leuktetumayen pu tremkawin (Acuérdense de nosotros grande juntas) / Leuketumayen pu lamenwentru (acuérdense de nosotros hermanos) / Leuketumayen ñuke ale (acuérdate de nosotros madre luna)/ Leuketumayen chau antü (acuérdate de nosotros padre sol) / Leuketumayen pu alwe (acuérdense de nosotros almas) / Leuketumayen pu katriwekeche (acuérdense de nosotros gente de Pucatrihue)".

En el imaginario williche estas entidades están presentes en la rogativa, donde la gente se relaciona con los elementos numinosos de la naturaleza y los espíritus ancestrales se mueven por los arcos. Como mostraremos, estas ideas se manifiestan de modo recurrente en los sistemas religiosos cosmovisionarios andinos, donde encontramos importantes paralelismos en los patrones rituales (ver Figura 4).

\section{Puente de estrellas}

En la comunidad de Maihue, situada en los márgenes del río Pilmaiquén, se expresa en el rewe una asociación de elementos figurativos que resulta relevante en términos de las relaciones simbólicas y recurrencias interculturales que plantea. Al centro del arco se encuentra una cruz elaborada con flores, que disturba el patrón iconográfico característico del arcoíris y plantea una representación dualista de este motivo. Se trata, hasta donde conocemos, de una asociación que no se repite del mismo modo en el contexto etnográfico williche, pero se encuentra con variantes en Tringlo, donde al centro del rewe se dispone una corona de flores. Lo interesante de la asociación figurativa del arco y la cruz es que ésta tiene un correlato astronómico y se halla reproducida en el arte rupestre del área del río Manso, vertiente oriental de la cordillera de los Andes. El sitio 


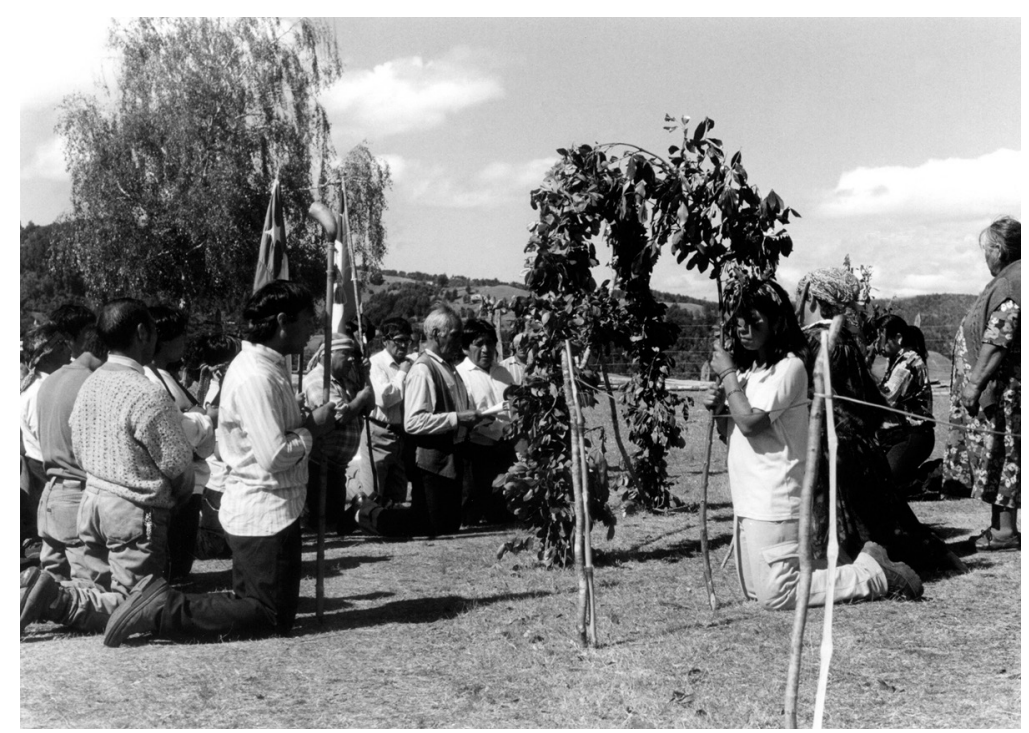

Figura 4. Arco de la interrogación en Lafquenmapu, San Juan de la Costa.

denominado Peumayén 2 (Podestá et al. 2009), ubicado en el paralelo 42 al sur del lago Nahuelhuapi, presenta un registro abundante de estas figuras con un dimorfismo en sus patrones de representación que resulta significativo.

Allí, en un paredón que mira al río Manso, se encuentra el diseño de un arco asociado a una cruz y una pareja de personas bajo estos elementos con las manos alzadas, en actitud ritual (ver Figura 5). La datación de la pintura rupestre de este sitio, de acuerdo a la información contextual, la sitúa entre los años 700 y 1300 de nuestra era (op. cit.). Si bien no es posible demostrar la relación de esta imagen con las prácticas cúlticas mapuche del presente, en relación a su estructura de sentido, los datos contextuales y la correlación de elementos simbólicos son consistentes con esta hipótesis interpretativa. En primer lugar, porque el sitio se encuentra en territorio ancestral williche, distante a aproximadamente 100 kilómetros al sur de la cancha de rogativa de Maihue. En segundo término, porque su arte rupestre tiene un rango de temporalidad que permite adscribirlo al marco de sus antecedentes de la cultura williche. En tercer lugar, porque la imagen reproduce una escena que es posible observar hasta hoy en el lepün. En la rogativa de Tringlo, por ejemplo, los kamaskos hacen un afafán, grito de avivamiento ritual con sus brazos alzados frente al arco.

Los investigadores del sitio Peumayén 2 (Podestá et al. 2009) interpretan la imagen de paredón como un arcoíris, en virtud a la frecuencia de este fenómeno atmosférico en río Manso. No obstante, el panel muestra variantes figurativas que resultan relevantes. A ambos lados del motivo del arco y la cruz se encuentran arcos simples, lo que plantea una representación dual que distingue cualitativamente pero homologa funcionalmente a dos referentes. Se trata - como mostraremos- de fenómenos naturales que se encuentran recurrentemente vinculados a la figura del arco en el espacio andino: al arcoíris o arco diurno y la Vía Láctea o arco nocturno. En este último, concurren fenoménicamente las figuras del arco y la cruz. Al respec-

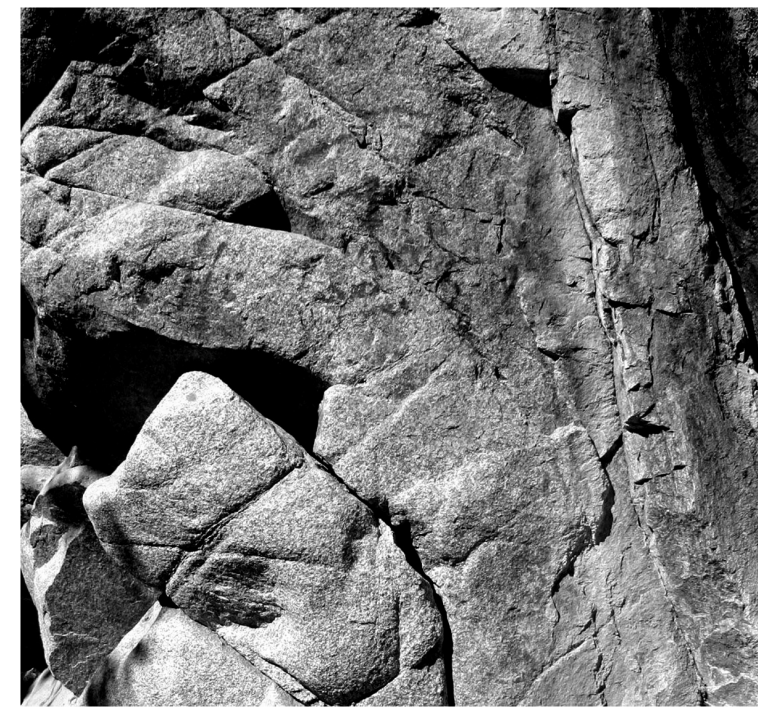

Figura 5. Asociación entre el arco y la cruz, en Peumayen 2. 
to se debe notar que la constelación de la Cruz del Sur alcanza su posición cenital a comienzos de mayo, quedando situada al centro de la Vía Láctea, la que se proyecta en la bóveda celeste como un arco. Esta asociación simbólica se encuentra ritualizada en la sociedad andina, donde se la celebra en forma cúltica.

Así sucede, por ejemplo, en San Pedro de Atacama, que dispone de uno de los cielos más prístinos del planeta, donde podemos apreciar esta conjunción estelar la noche del dos al tres de mayo, cuando la constelación de la Cruz del Sur adopta su posición cenital. Para los atacameños, la Vía Láctea es el "río de estrellas", también conocido como "río Jordán", y representa a las almas de los difuntos en su recorrido hacia la otra vida (Cruz et al. s.f.). La constelación de la Cruz del Sur, también denominada "Pata del Suri", se considera, al igual que en el mundo aymara, una puerta de entrada hacia el mundo de los muertos, un puente. Su alineación al centro de la Vía Láctea adquiere un profundo sentido simbólico. Se trata de un hito astronómico ritualizado desde el período prehispánico y que se celebra hasta el presente en el mundo andino, bajo la advocación de la Santa Cruz. Constituye una fecha en el calendario cúltico católico conocida como la "fiesta de las cruces" o "fiesta de la Cruz de Mayo". En el ciclo agrícola, señala para los atacameños el inicio del período de descanso de la tierra. En el marco de esta celebración, los comuneros visten las cruces, las que se consideran protectoras del espacio comunitario. No obstante, en la memoria ancestral de los habitantes de Atacama, la fecha tiene también un sentido más íntimo. Por la posición que adopta la Cruz del Sur, en el centro de la Vía Láctea, desplegada en $180^{\circ}$ grados, se considera que es uno de los momentos en el año en que está tendido el puente que permite el encuentro de las almas de los difuntos con sus deudos (ver Figura 6 y 7 ).

En palabras de Cruz et al. (s.f.: 141):

"En su rol de guía, la Cruz del Sur circunscribe períodos culturalmente sensibles del año, reflejado en los momentos de encuentro entre las almas de los difuntos con sus deudos. Considerada una puerta de acceso a otras dimensiones de espacio y tiempo, la Cruz del Sur marca con su recorrido el punto cúlmine del Río, en cuanto máxima posición en el firmamento. De ahí su función comunicativa y ordenadora de espacio tiempo entre la Tierra y el Cielo".

Esta función simbólica, articuladora del mundo de los vi-

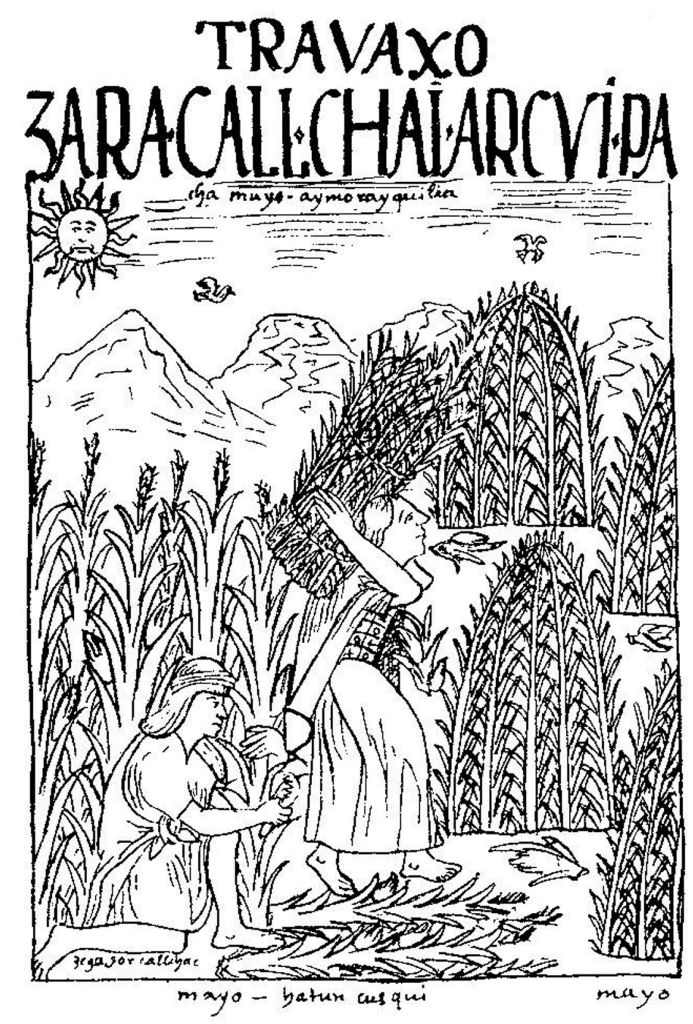

Figura 6. Guamán Poma representa a las plantas de maíz formando un arco al momento de su cosecha, en el mes de mayo.

vos y de los muertos, que se atribuye a la conjunción entre el arco de la Vía Láctea y la constelación de la Cruz del Sur se expresa con más fuerza seis meses más tarde de la fiesta de las cruces. La fecha correspondiente es la del "Día de Todos los Santos y de Todos los Muertos", el uno y dos de noviembre, cuando la Cruz del Sur alcanza el acimut, es decir, la posición más próxima al horizonte. Entonces es posible ver el arco de la Vía Láctea y su río de estrellas, desplegado hacia el poniente y la Cruz del Sur tocando el horizonte oeste. De acuerdo a los atacameños, por allí bajan las almas, que tienen permito durante estos días para volver a la tierra, donde son esperados por sus deudos. El 31 de octubre los familiares acuden al cementerio para adornar y limpiar las tumbas, propiciando la llegada de las almas. Mucho manifiestan su intención llevando la cruz de la tumba hasta su hogar y disponiéndolas en el centro o frontis de las mesas de difuntos. Éstas deben estar constituidas para el primero de noviembre, cuando llegan las almas. Para estos efectos, disponen en una de las habitaciones principales de la casa un mesón grande, 


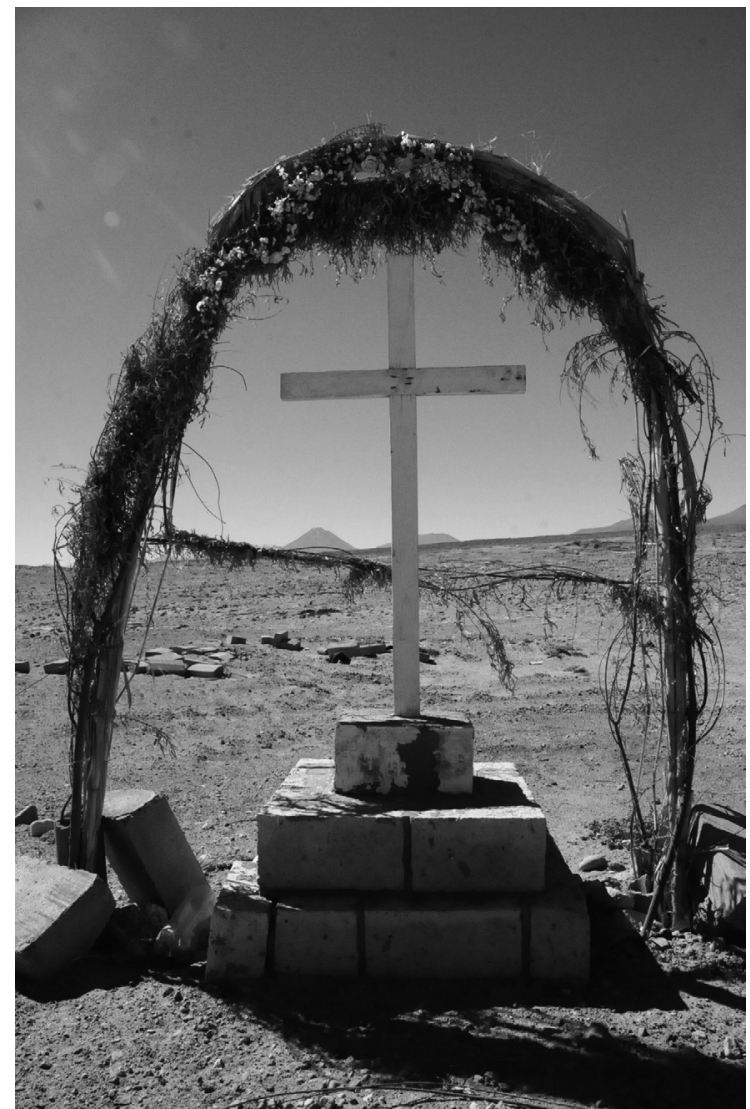

Figura 7. Asociación del arco y la cruz en fiesta de la Cruz de Mayo de San Pedro de Atacama.

cubierto por un mantel blanco o negro, en caso de tratarse de un alma fresca. A su cabecera levantan una suerte de altar escalonado, que es circundado por un arco vegetal de palmas o cañas de azúcar. La función de este último es guiar al difunto hasta la mesa. En palabras de la señora Leonor Mamani: "mi abuelita decía que este día se abren las puertas del cielo para que vengan las almas, por lo que tenía que estar levantado el arco para recibirlas, porque si no lo encuentran las almas se van y el año va a ser muy malo". Un dato referido por esta misma fuente que reafirma la función mediadora del arco es su uso en el pasado en los velorios, en la cabeza de las mesas donde se situaba a los muertos (ver Figura 8 y 9 ).

Las mesas de difuntos del Día de Todos los Santos, en uso hasta la actualidad, son servidas con abundancia y cuidado para la atención del alma. La señora Leonor Mamani nos dice que para esta ocasión se deben atender los gustos del finado:
"Se le prepara especialmente los platos de su preferencia. Si era bueno para el trago se le deja una jarra de vino, si le gusta fumar se le compran sus cigarros. Se le deja agua para calmar su sed y frutas frescas para alimentarlo. El arco se adorna con flores, de él se cuelgan dulces y frutos de la estación para que coman los angelitos, niños difuntos que acompañan al alma. En el altar se ponen escaleras de pan para ayudarle a bajar del cielo. Al centro del arco se para un cordero asado completo".

En torno a esta mesa se reciben a familiares y amigos del difunto, atendidos con bebidas, café y licores fuertes, que permanecerán rezando y cantando coplas, hasta el alba, hora en que la mesa se reparte entre todos quienes acompañaron la velada. Según nos informa la antropóloga Ana María Lemus en la localidad de Toconao, para despachar el alma, el arco se lleva hasta la tumba del difunto en el cementerio.

Las formas simbólicas y estructura semántica de este proceso ritual presentan un notable paralelismo con los ngillatun lelfunche de Lago Ranco y Río Bueno. En estos, el arco

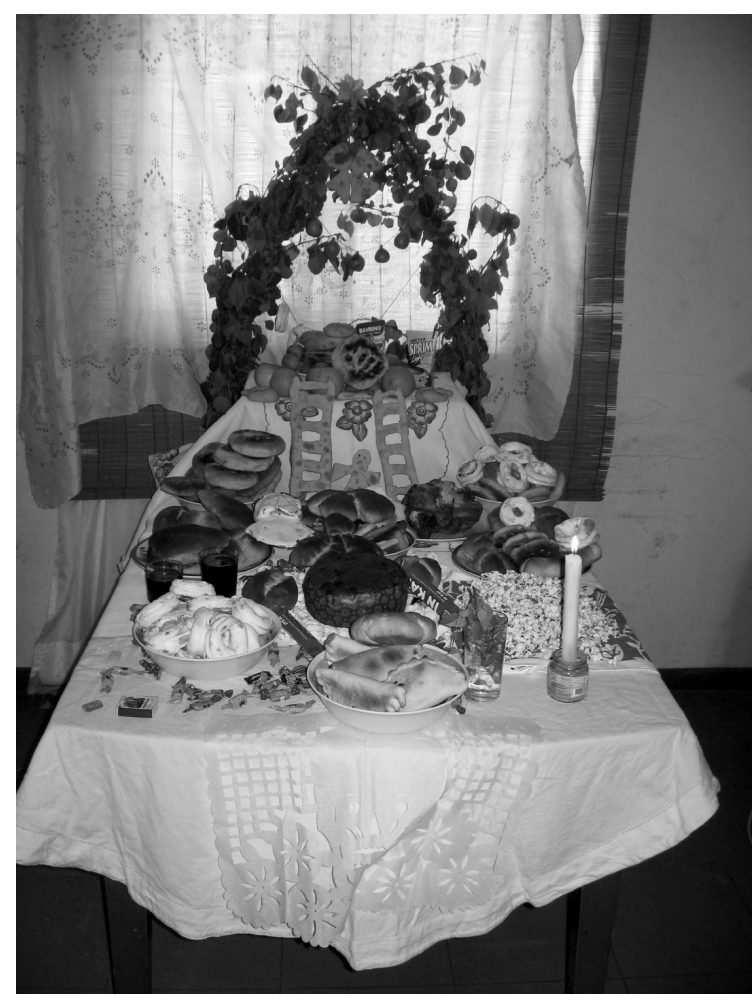

Figura 8. Recepción de almas a través del arco el día de difuntos en San Pedro de Atacama. Fotografía: Jimena Cruz. 


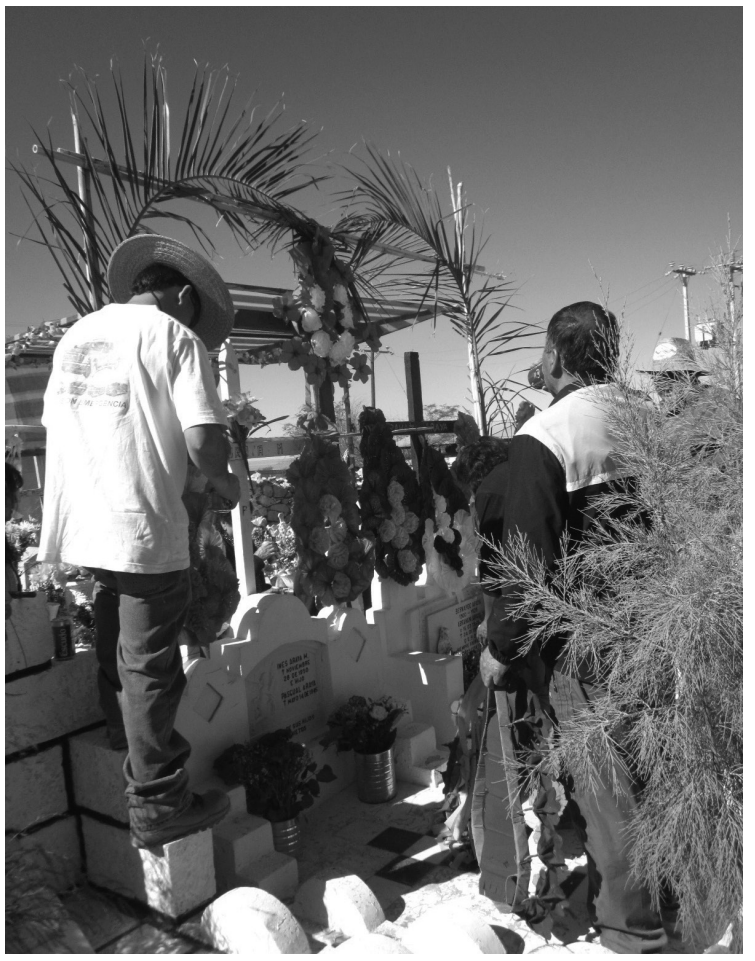

Figura 9. Despacho de almas con arco en el cementerio de Toconao. Fotografía: Ana María Lemus.

opera como un portal por donde se mueven los espíritus tutelares y se produce la congregación de los antepasados y los miembros de las organizaciones rituales. Mientras el arco de difuntos representa a la Vía Láctea y se emplaza en el espacio familiar, el arco del niillatun representa al arcoíris y actúa en contexto ritual comunitario, pero su función es la misma: servir de umbral simbólico a través del que se produce el movimiento de los espíritus. En ambos casos el arco es un operador ritual provisto de capacidad realizativa, en el sentido pragmático del término (Austin 1998). Su uso establece hechos simbólicos socialmente reconocidos. Los deudos atacameños levantan arcos para guiar hasta sus casas a las almas de sus parientes, que bajan por el río de estrellas. Los kamaskos williche erigen arcos para comunicarse con las deidades con ayuda de los espíritus mediadores y participación de los ancestros. En ambos casos se produce una comunidad restaurada en la que conviven sujetos históricos y espíritus ancestrales gracias a la disolución de las coordenadas espaciotemporales que convergen en el arco, donde el presente se funde con el pasado y las diversas dimensiones del universo se encuentran. Entre los mapuche y atacameños, el umbral que representa el arco es símbolo de trascendencia.

\section{Arco de la serpiente}

El motivo del arco se encuentra profusamente representado en el mundo andino, al menos desde el período Intermedio Temprano, bajo la forma de una serpiente bicéfala que la mitología identifica como "el Amaru" (Taylor 2001). En la iconografía de la cultura Moche, y posteriormente en la Casma, aparecen recurrentemente figuras de personajes sobrenaturales bajo el arco de la serpiente, el que es alternativamente interpretado como una representación de la Vía Láctea (Makowski 1996, 2000; Golte 2009) o el arcoíris (Carrión 2005). Si bien no se puede pretender que estas manifestaciones icónicas se encuentren directamente emparentadas al simbolismo del arco en la cultura mapuche, ellas muestran la profundidad histórica que tiene el motivo en el área cultural central andina (sensu Lumbreras 1981) y la persistencia en el marco de un sistema de trasformación de sus representaciones. A partir del cruce de la información mitológica, etnohistórica, etnolingüística y etnográfica se ha constituido un canon interpretativo del arco de la serpiente bicéfala en el espacio central andino (Carrión 2005; Hocquenghem 1987; Uceda 2004a y 2004b), que lo considera un simbolismo de conexión entre niveles del universo. La referencia a estos antecedentes iconológicos es importante para comprender la antigüedad de este motivo y su continuidad en el mundo andino. Si bien este no se hace presente en todas las culturas del área, se trata de un motivo recurrente, que reaparece luego de manera importante en el incario y se proyecta en las prácticas rituales de las comunidades andinas del presente.

Respecto a su importancia, nos informa Carrión 2005: 47): "Los dioses de mayor rango de la iconografía postclásica del norte, se hallan debajo de este arco como si se tratara de un techo o halo celeste, estableciéndose un nexo de unión entre las funciones de estos dioses y las del dragón bicéfalo. Además la serpiente bicéfala se convierte en insignia o atributo de los dioses que desempeñan funciones pluvíferas o generadoras, en cuyo caso adopta la forma de corona o vincha, de un cinturón o un cetro".

La serpiente bicéfala anuda en su campo de referencias a la Vía Láctea y el arcoíris, asociándolos al agua y la fertilidad. La primera se designa en quechua Ch'aska Mayu, que significa "río de estrellas". A esta galaxia se le considera la contraparte sideral de los ríos terrestres y reservorio de las aguas que riegan la tierra (Gisbert 2008). Al segundo se 
lo denomina kuichi y también se vincula simbólicamente al ciclo del agua (Cáceres 2002). Como señala BouysseCassagne (1988: 93), "este último está asimilado a una gigantesca serpiente que nace de una fuente, cruza el cielo y entierra una de sus dos cabezas en otra fuente más distante". Zuidema (referido en Valko 2005) señala que el arcoíris absorbe el agua de las profundidades de la tierra y la conduce hasta el cielo, desde donde precipita. Ortmann (2002) sostiene que el Amaru es símbolo del agua y su poder es tanto germinador como destructor. Esta posee una capacidad vitalizante, pero cuando sobreabunda produce los waiko, como se denomina a los aludes, cuya acción resulta devastadora. El arco connota, por lo tanto, las ideas de vida y regeneración (kawsa), muerte y trasformación (pachakuti). Su figura cruza y enlaza las distintas dimensiones del cosmos, estableciendo una vía por la que transitan las fuerzas espirituales. Como apunta Sánchez Garrafa (2013: 5) “La Vía Láctea o Mayu, río sideral, se conecta por sus extremos con otro río que corre por el inframundo y que suele considerarse como el río de la muerte o el río de los muertos".

En este sentido, el registro iconográfico moche es bastante sugerente. Uceda (2004a, 2004b, 2008) analiza una serie de escenas pictográficas sobre cerámica que muestran el desarrollo de actividad ritual en torno a la figura del arco de la serpiente bicéfala. En ellas se aprecian personajes especialmente ataviados, consumiendo sustancias psicoactivas, algunos en estado de éxtasis. Una de estas escenas muestra a un personaje con colmillos bajo el arco, rasgo que se considera significante de una condición sobrena- tural. Lo interesante de la serie es que los sujetos portan piezas de vestuario encontradas entre la evidencia arqueológica de la Huaca de la Luna. En los frisos situados en el entorno de la plaza mayor de este templo se encuentra un motivo complejo que puede ser interpretado como una representación del cosmos moche (Sánchez Garrafa 2012). En él destaca la figura de un hombre tendiendo un lazo curvo hacia una chacana (cruz andina) con cola de pez, que podría representar el movimiento de la Cruz del Sur en la Vía Láctea o "río de la estrellas", por cuyo curso navega entre el tres de mayo (posición cenital) y el dos de noviembre (acimut). El conjunto iconográfico previamente referido ha sido signado como "Los sacerdotes del arco bicéfalo" (Uceda Op. cit). La anfisbena o serpiente de dos cabezas de figura arqueada se interpreta aquí como una puerta interdimensional a través de cuyo umbral especialistas rituales acceden al mundo de las deidades y ancestros (ver Figura 10).

En el área andina el arco funciona simbólicamente como un articulador de tiempos y espacios, un elemento mediador o intermediario que, como señala Cereceda (1988: 344), "tiende un puente curvo entre las profundidades del mundo y el cielo". Por su persistencia en el tiempo, su asociación a valores sociales y condensación de significados cosmovisionarios, López Baralt (1986) lo considera un símbolo central del mundo andino, cuya vigencia se mantiene hasta el incario. En palabras de Garcilaso (2012: 230), los gobernantes incas tomaron al arco del cielo "por divisa y blasón, porque se jactaban descender del sol”. En la cosmovisión incaica, este motivo se asocia figurativamente al Amaru, la serpiente, que conecta los niveles del

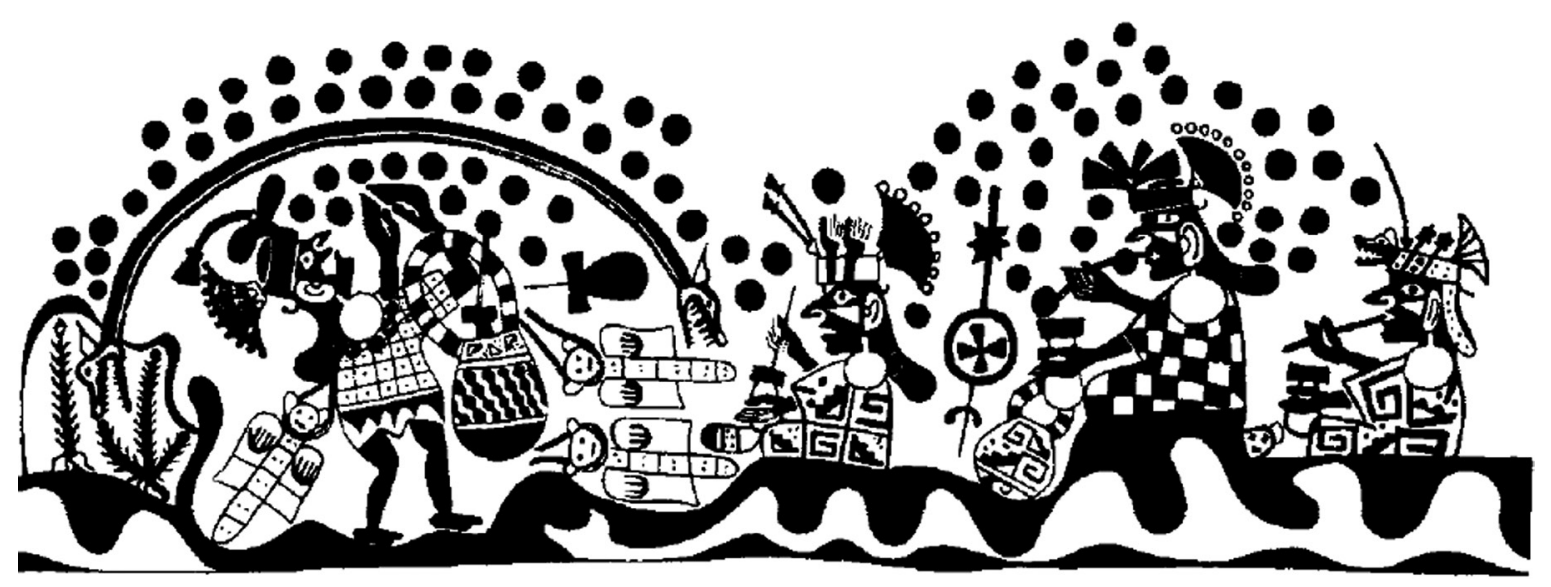

Figura 10. Iconografía moche representando un motivo denominado "sacerdotes del arco". Dibujo de Donna McClelland. 
universo (Steele y Allen 2004). Según el testimonio de Acosta (1894: 10) "adoraban el arco del Cielo, y era armas ó insignias del Inca con dos culebras á los lados á la larga". Ejemplo de ello es el escudo de armas del propio inca Garcilaso, que incluye la representación de un arcoíris emergiendo de la boca de dos serpientes. Desde el arcoíris cuelga una mascaipacha, borla multicolor que constituía un emblema distintivo del sapa inca o emperador. Este diseño muestra la complejidad del simbolismo del arco, vinculado a las fuerzas telúricas del subsuelo y que se proyecta hacia el cielo. De allí igualmente su ambivalencia, propia de elementos sagrados que resultan poderosos y peligrosos y suscitan simultáneamente respeto, veneración y temor, como lo muestra el trabajo de García (2007) sobre el arcoíris en el mundo centro andino, cuya lectura oscila entre las ideas de fecundidad y enfermedad, reproducción y destrucción. Cronistas como Ondegardo (1990) y Murúa (2001) coinciden en señalar que la aparición del arcoíris atemoriza, pero se le tiene respeto y trata con veneración. Agregan otro dato más, los runa creen que los arcos se levantan desde lugares donde hay fuentes de agua o manantiales subterráneos. Hasta el día de hoy, en las inmediaciones de Cusco se mantiene el uso del arco efímero cubierto de flores para interceder con los espíritus dueños del agua durante las ceremonias de culto a las vertientes.

En la narrativa mítica, el símbolo de arco señala los orígenes del incario. Santa Cruz Pachacuti (1995) afirma que a Manco Capac se le aparece un arcoíris en la cima del cerro Huanacauri, señalando el lugar de la fundación de Cusco y el inicio de una nueva era que dará lugar al desarrollo del imperio incaico. Por lo mismo, la wipala o estandarte del Tawantinsuyo lleva sus colores. En la religión oficial, el arcoíris es venerado como hijo del sol en el santuario del Coricancha. Según Garcilaso (2012: 230), allí sobre planchas de oro "tenían pintado muy natural el arco del cielo, tan grande que tomaba de una pared a otra, con todos sus colores al vivo". Guaman Poma de Ayala agrega que los sacerdotes producían artificialmente un arco de luz a través de cuya elipse cromática oraba el inca: "todas la paredes altas y bajas estaban guarnecidas de oro finísimo, y en lo alto del techo estaba colgados muchos cristales, y a los dos lados dos leones apuntando al sol, alumbraban de las ventanas la claridad de las dos partes soplaban dos indios [ ] y salía un arco que ellos llamaban cirichi; y allí en medio se ponía el Inga hincado de rodillas puestas las manos en el rostro frente al sol y a la imagen del sol, y decía

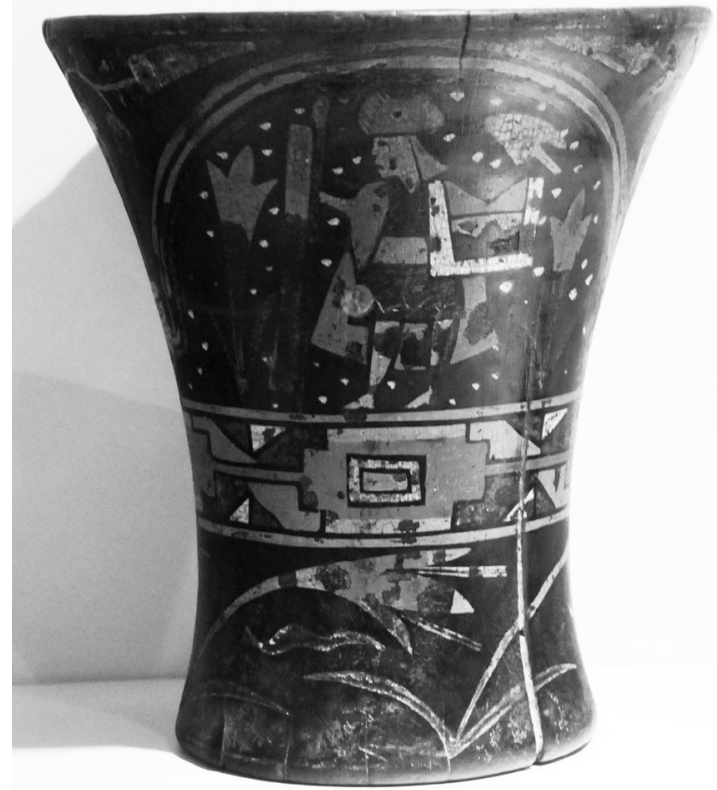

Figura 11. Personaje inca representado en torno al arco. Quero del Museo Inca de Cusco.

su oración" (1980: 185). El arco de luz se presenta como un instrumento mediador, vía de comunicación divina. Como contrapunto, el sapa inca o emperador se representa emergiendo de la misma figura. Durante las fiestas egregias, el soberano transitaba bajo grandes arcos llamados sirichi, compuestos de flores y chafalonía (Rosat 2009). De modo recurrente, la iconografía de los queros retrata la figura del inca situado bajo el arco iris, como un modo de señalar su filiación divina, que le confiere el carácter de hijo del sol. En el mundo inca, el arco opera como un umbral, constituye un símbolo de trascendencia, conexión con lo sagrado y transitividad a través de la dimensiones espacio temporales (Steele y Allen 2004), rasgos que se proyectan sobre las culturas andinas del presente (ver Figura 11).

\section{Punku, tinku y ayni}

El término iphalla designa en lengua quechua al arco portátil de flores y frutas que acompaña el traslado de los novios durante el ritual matrimonial andino (Lira y Mejía 2008). Se trata de una costumbre prehispánica, registrada desde la época del Tawantinsuyo, donde centenares de arcos marcaban el paso del príncipe heredero y su pareja el día de su boda (Rosat 2009). Este elemento figurativo se encuentra vigente hasta la actualidad en casamientos quechuas (Ulfe 1997) y aymaras (Izko, Molina y Pereira 
1986), donde se lo emplea como un umbral que señala la constitución de la pareja y su paso a una nueva vida en común, y también como espacio para la entrega de presentes, a través de los cuales expresan las relaciones de solidaridad del grupo. Los arcos bajo los que se sitúan y desplazan los recién casados son levantados por los padrinos y amigos de los novios, engalanados con telas donde se prenden los aportes en dineros, objetos de plata y los enseres que se les lleva de regalo. Similar función cumplen los arcos en el ritual aymara del corte de los primeros cabellos (uma ruthuku), que señala el paso de la primera infancia a la niñez. En esta ceremonia, cada trozo de pelo cortado por los padrinos implica una ofrenda que se entrega al menor, para ayudarle a recorrer el camino de su vida. La relación que se establece de esta manera se considera una forma de "parentesco espiritual", porque "cada acto de dar implica energía vital intercambiada, trascendiendo los términos puramente materiales o el interés económico" (Delgado 2002: 226).

Por lo mismo, el arco ha devenido en este contexto cultural en el símbolo del ayni (Damen 1996), concepto que designa las relaciones de ayuda mutua y el principio de reciprocidad. El término también se emplea para referir a los aportes que realizan los participantes a las festividades religiosas o comunitarias, aunque en ellas el diseño material del arco no se encuentre necesariamente presente. En el caso de las celebraciones patronales o de las advocaciones de la Virgen, estas donaciones suelen consistir en cajas de cerveza, que se entregan al "pasante" para el consumo comunitario, a las que se llama arku. Del mismo modo, el término refiere al resultado del esfuerzo del trabajo colectivo en la minqa, como puede ser la pila de sacos de papas producto de la cosecha, en la que los asistentes prestan voluntariamente su mano de obra, a cambio de comida, hojas de coca, chicha y el compromiso de reciprocidad.

En los pueblos aymaras, el arco se levanta también con ocasión de los eventos cívicos, por la recepción de obras comunitarias o la visita de autoridades políticas y administrativas, a las que se les hace pasar o recibe bajo su umbral. No obstante, como muestra van Kessel (1982) y lo ratifica Motta (1985), no se trata solo de un elemento emblemático de la sociabilidad andina, sino de un símbolo de la religiosidad precolombina, al que califican como "arco de la vida". Este se encuentra presente en los rituales del ciclo productivo que se ofrece a los Mallkus (espíritus de las montañas), la Pacha Mama (madre tierra) y el Amaru (dueño del agua), donde se expresan las coordenadas simbólicas que estructuran el mundo aymara. La organización del espacio en esta cultura tiene una orientación simbólica hacia el oriente, punto desde el que se levanta el sol (Motta 2011), al que se asocia con la vida y la fertilidad. Por el contrario, el oeste se asocia con la muerte, dirección hacia donde marchas las almas siguiendo los pasos del sol.

En el territorio aymara chileno, el este es también el lugar de emplazamiento de las grandes montañas, desde donde fluye el agua, las que son consideradas espíritus ancestrales de las comunidades, conocidos como Mallku (si es masculino) y Talla (si es femenino). A estos se les rinde culto el mes de febrero, durante los llamados "día del compadre" y "día de comadre", que preceden a la entrada del carnaval. Así, por ejemplo sucede en Isluga (Martínez 1976). Según van Kessel (1982), para el día de compadres los comuneros suben hasta el cerro donde habita el espíritu tutelar y levantan un palo vestido en forma de pastor, cuidadosamente engalanado, que denominan "arco" y representa al Mallku. Su propiciación contempla una wilancha (sacrificio animal), asperges de sangre, ofrendas de coca, alcohol, oraciones, una comida comunitaria, bailes y un diálogo consultivo con el espíritu del cerro sobre los problemas de la comunidad. El arco cumple aquí la función de punku, puerta virtual a través de la que se desplaza el espíritu para producir el tinku, encuentro ritual con él, donde junto con el espacio de comunión, se ponen en evidencia la construcción de los límites que marcan las dimensiones del universo andino. Ello se deja ver, igualmente, en los arcos que coronan los altares o mesas rituales cubiertos de alimentos que los aymaras levantan el día de difuntos para recibir a las almas (Fernández 2006) (ver Figura 12 y 13).

En su doble carácter de límite y punto de encuentro, el arco es una metáfora que muestra la estructura del espacio tiempo aymara: un espacio estratigráfico pero interconectado, un tiempo cíclico que conecta los espacios. Al respecto nos dice van Kessel (1982: 278):

"El arco de la vida, que observamos en el triple culto, se levanta en el Oriente, cubre el mundo, y desciende en Occidente. Como ciclo este arco significa precisamente: 'Nueva vida de la muerte', esto referente a la economía agrícola (la semilla cae en la tierra, muere y produce nueva vida) como también la economía ganadera (la huilancha o víctima sacrificada, que recibe un entierro ritual y 


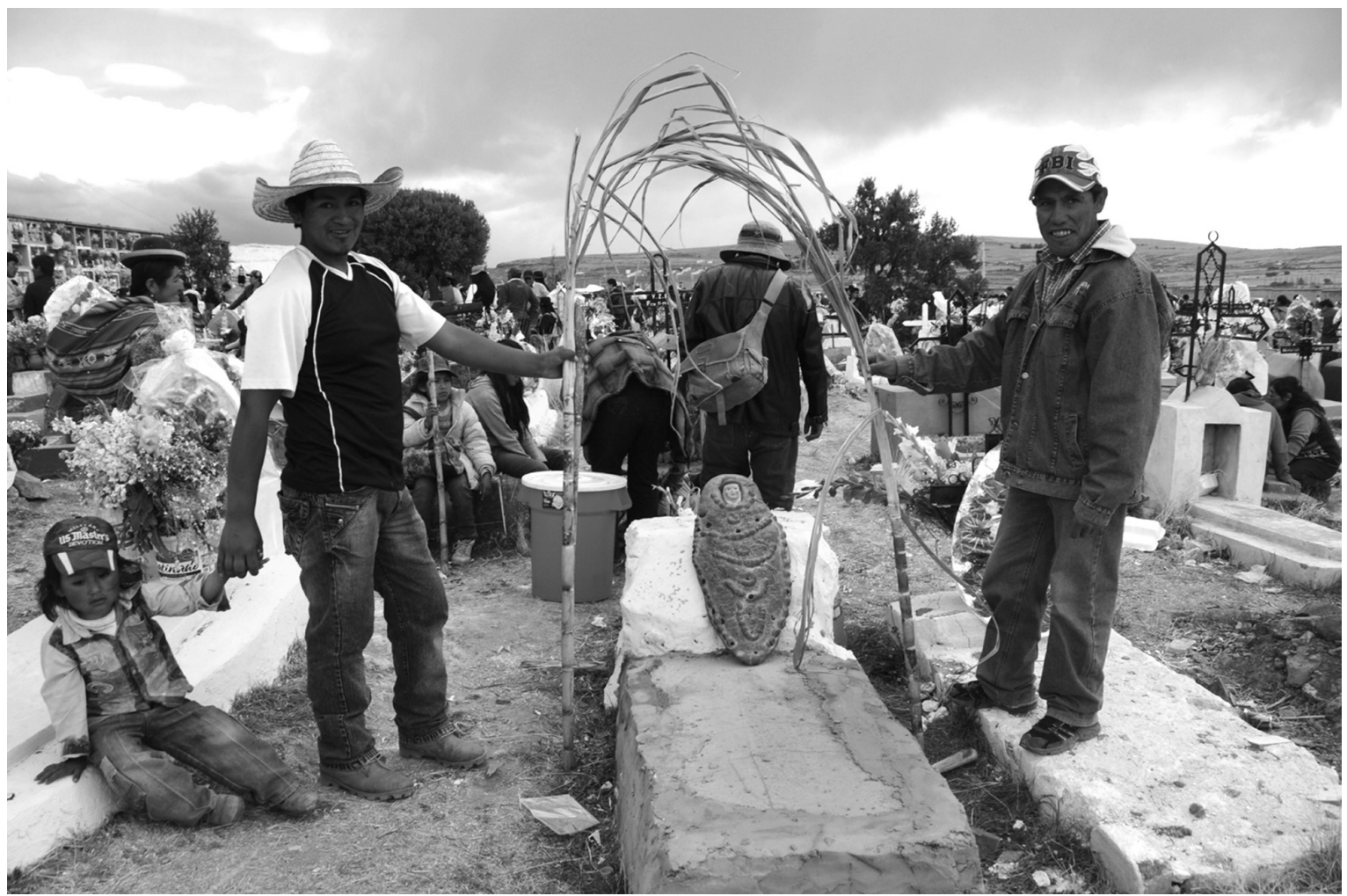

Figura 12. Deudos aymaras levantando un arco para la recepción de almas en cementerio de Yanamayo, Puno.

asegura la nueva crianza del ganado, considerada como resurrección) y aún hace referencia a la comunidad humana misma (que a través de la muerte, entierro y culto a los antepasados, se renueva constantemente)".

El tiempo del carnaval aymara entra y sale a través del arco, mostrando igualmente el devenir del tiempo cíclico y la articulación circular de los niveles del cosmos, donde el mundo de arriba conecta con el de abajo. Así sucede en la comunidad de Chaca en el valle homónimo. Allí, el ciclo festivo se inicia con el desentierro de "Ño Carnavalón", el espíritu del carnaval que se asocia a los ancestros que llegan con él y se representa en la forma de un muñeco de trapo. Su cuerpo es recuperado del ukupacha, mundo de abajo, para incorporar a su espíritu que vive en el alaxpacha, mundo de arriba. La entrada del carnaval se produce a través del tránsito performativo a través del arco que separa a la vida de la muerte. El término del carnaval supone la inversión de este acto ritual. En este caso, No Carnavalón sale por el arco despidiendo el tiempo festivo y se lo deja descansando tras él, para luego ser nuevamente enterrado. Tras cruzar el umbral, su espíritu retorna al alaxpacha, su

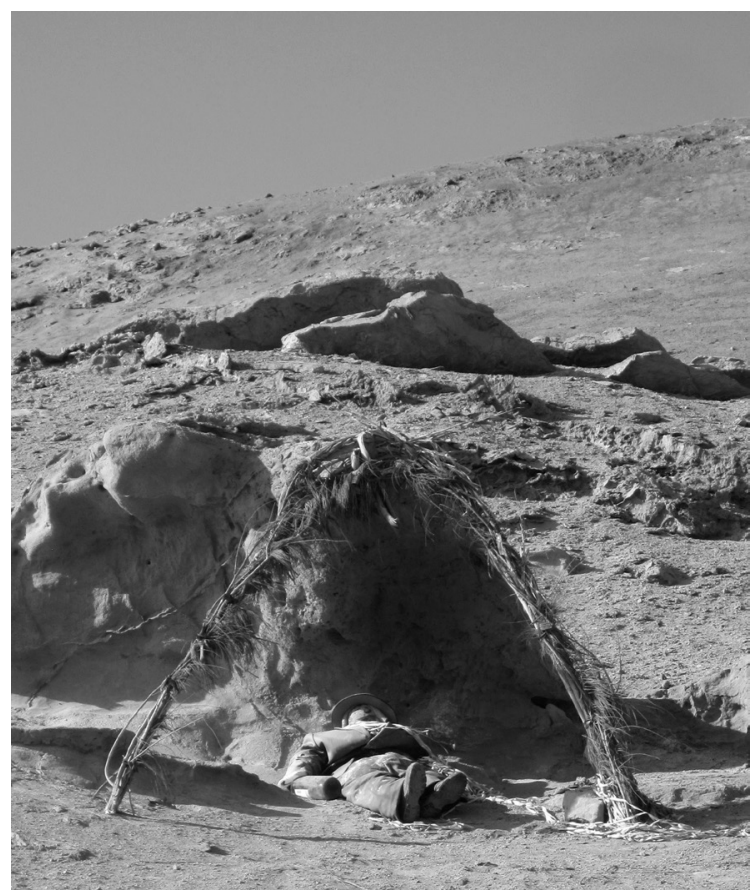

Figura 13. Despacho de Ño Carnavalón a través del arco en comunidad de Chaca, Región de Arica y Parinacota. 
cuerpo es devuelto al ukupacha. Los ancestros se van con él. El paso por el arco inicia y cierra el ciclo a través del que se mueve el tiempo de carnaval en el que se encuentran y sintetizan los niveles del universo, para reunir a vivos y muertos. El umbral del arco también es aquí símbolo de conexión y trascendencia de los límites cronológicos y topográficos que separan el ciclo vital del mundo espiritual.

\section{Correlatos paradigmáticos}

El simbolismo del arco muestra recurrencias figurativas, cognitivas y funcionales en los contextos socioculturales que hemos referido, revelando un marco de representaciones compartidas que asume un carácter cotradicional. Este correlato permite inferir la existencia de relaciones interculturales históricamente trazadas cuyo origen y desarrollo es una tarea por dilucidar. De modo constante, el arco expresa y opera como un portal que permite el tránsito de entidades espirituales por espacios interdimensionales. Por su textura nodal, permite observar el correlato de paradigmas cosmovisionarios, es decir, de los metamodelos (modelos de modelos) sobre el universo en aspectos como su diseño, los niveles que lo conforman, las interacciones, espacios y modos de conexión entre estos, las entidades que los habitan y sus desplazamientos. El arco se perfila, así, como un símbolo panandino cuyo sistema de trasformaciones - que aquí denominamos "etnopoéticas del umbral”- expresa una matriz ideológica común.

La figura del portal implica la noción de límite. Su trazado simbólico constituye un umbral que delinea a la vez que permite trascender los puntos de demarcación que señalan la frontera entre distintos planos y niveles de realidad. El arco trenzado de flores que representa al arcoíris situado en el centro de las canchas de los ngillatun williche en las comunidades de Maihue, Nolguehue y Tringlo, ilustra de manera ejemplar el sistema de coordenadas simbólicas que ordena el mundo mapuche. Su emplazamiento y materialidad hace ostensible el diseño imaginario del espacio. Enunciados performativamente a través de su contorno y orientación, en él se intersectan dos ejes que se articulan de modo circular, desplegado en un sentido vertical, el primero, y en un sentido horizontal, el segundo. El primero vincula los niveles de la Minche Mapu (mundo inferior), el NagMapu (mundo intermedio) y el Wenu Mapu (mundo de arriba); el segundo, al Puel Mapu (oriente) y el Lafken Mapu (occidente), que se consideran alternativamente puertas de acceso a los mundos superior y subterráneo. Se plantea así un juego de asociaciones que Grebe e Hidalgo (1988) han documentado en el caso atacameño y que van Kessel (1982) y Motta (2011) registran para el aymara. En dichas culturas, el este también se vincula al espacio de arriba, y el oeste al espacio de abajo, los que a su vez se encuentran relacionados a lo diurno y la vida, el primero, y a lo nocturno y la muerte, el segundo. El arco andino es un punto de mediación entre estas coordenadas del espacio tiempo, de allí su figuración doble como arcoíris y Vía Láctea, arco del día y de la noche.

En términos pragmáticos, el símbolo del arco es un instrumento ritual que permite operar sobre los límites de estas coordenadas de espacio tiempo, para moverse a través de ellas accediendo a otros niveles de realidad o para producir el encuentro en este plano con entidades espirituales que se localizan en ellas. A través de su umbral se desplazan los Ngen Mapu o espíritus tutelares de las comunidades mapuche williche en los lepün, y se personifica a los Mallkus y Tallas para el día de compadres entre los aymara. Su vano señala el camino a la otra vida para los espíritus de los difuntos en funerales williche y atacameños. Bajo su figura se muestran en éxtasis los sacerdotes moche y se mueve el machi filew (espíritu colaborador de la machi) en rituales de iniciación chamánicos williche. En el contexto aymara y atacameño, su trazado conduce a los espíritus de los difuntos hasta las mesas rituales preparadas por sus deudos, en el día de todas las almas. En todos estos casos, el arco permite trasponer las barreras del espacio y el tiempo, preferentemente para actualizar o hacer posible la presencia de la alteridad espiritual (espíritus tutelares, espíritus chamánicos, antepasados) con fines propiciatorios, performativos o conmemorativos. Pese a las diferencias entre los tipos rituales y contextos sociales, se advierte en ellos un claro correlato transcultural.

La comparación entre el lepün o nillatun williche de Lago Ranco y Río Bueno y el ritual de recepción de almas para el día de difuntos entre los atacameños ilustra de manera ejemplar los paralelismos en los paradigmas cosmovisionarios que los sostienen. El primero es un ritual comunitario de propiciación, dirigido a las deidades con la mediación de espíritus tutelares y donde se congregan, igualmente, los espíritus de los antepasados. El rewe de arco representa aquí al arcoíris, relmu, figurativamente constituye una puerta abierta hacia el mundo de arriba o Wenu Mapu, pero 
que conecta también al de abajo desde donde se levanta el arco. Bajo su umbral se recibe y atiende a los espíritus tutelares y se reúnen los ancestros. Unos y otros son aquí alimentados, en un acto de comensalidad que compromete y convoca a los miembros de las congregaciones rituales, los espíritus tutelares y ancestros. Concordante en diversos aspectos es el ritual de recepción de almas entre los atacameños, solo que en este caso se trata de un ritual familiar y de carácter conmemorativo, destinado a recibir a los espíritus de los muertos y ayudar a los recién fallecidos a concluir su viaje hacia el otro lado de la vida. En las vísperas del primero de noviembre, los deudos, particularmente quienes tienen almas frescas, levantan en sus casas mesas de difuntos para recibir a los espíritus. La estructura simbólica de estas mesas tiene una estratigrafía vertical, que reproduce la concepción del mundo atacameño. A la cabecera de ellas se levanta un arco, que debe guiar al muerto - y que representa al arco de la Vía Láctea por donde viajan las almas - hasta las mesas generosamente servidas con los alimentos para que compartan los muertos y sus deudos (ver Figura 14 y 15).
En los casos reseñados, el proceso ritual presenta un notable correlato. En ambos este se sitúa en el marco de una temporalidad cíclica, de un período que regresa e involucra actividad diurna y nocturna. La llegada del verano señala el tiempo de lepün entre las congregaciones williche de Lago Ranco y Río Bueno, que en Maihue se celebra para el solsticio estival, lo que antiguamente ocurría también en Nolguehue. En estas comunidades el proceso se inicia con un peregrinaje a las casas de los espíritus tutelares, situadas en las proximidades de los cementerios, en cuevas denominadas renü. Hasta allí concurren para invocar la presencia de estos mediadores en el ritual. Una vez realizado el ceremonial, regresarán allí para devolver a este sitio los elementos significantes del Ngen Mapu. El ritual de recepción de almas coincide con una alineación estelar de la constelación de la Cruz del Sur, que en el espacio centro andino preludia la temporada húmeda. Aquí el proceso se inicia el 31 de octubre con una visita al cementerio para invocar a los espíritus de los difuntos. De sus tumbas se toman las "segundas cruces", especialmente dispuestas para ser colocadas en las mesas de difuntos. El proceso ritual se

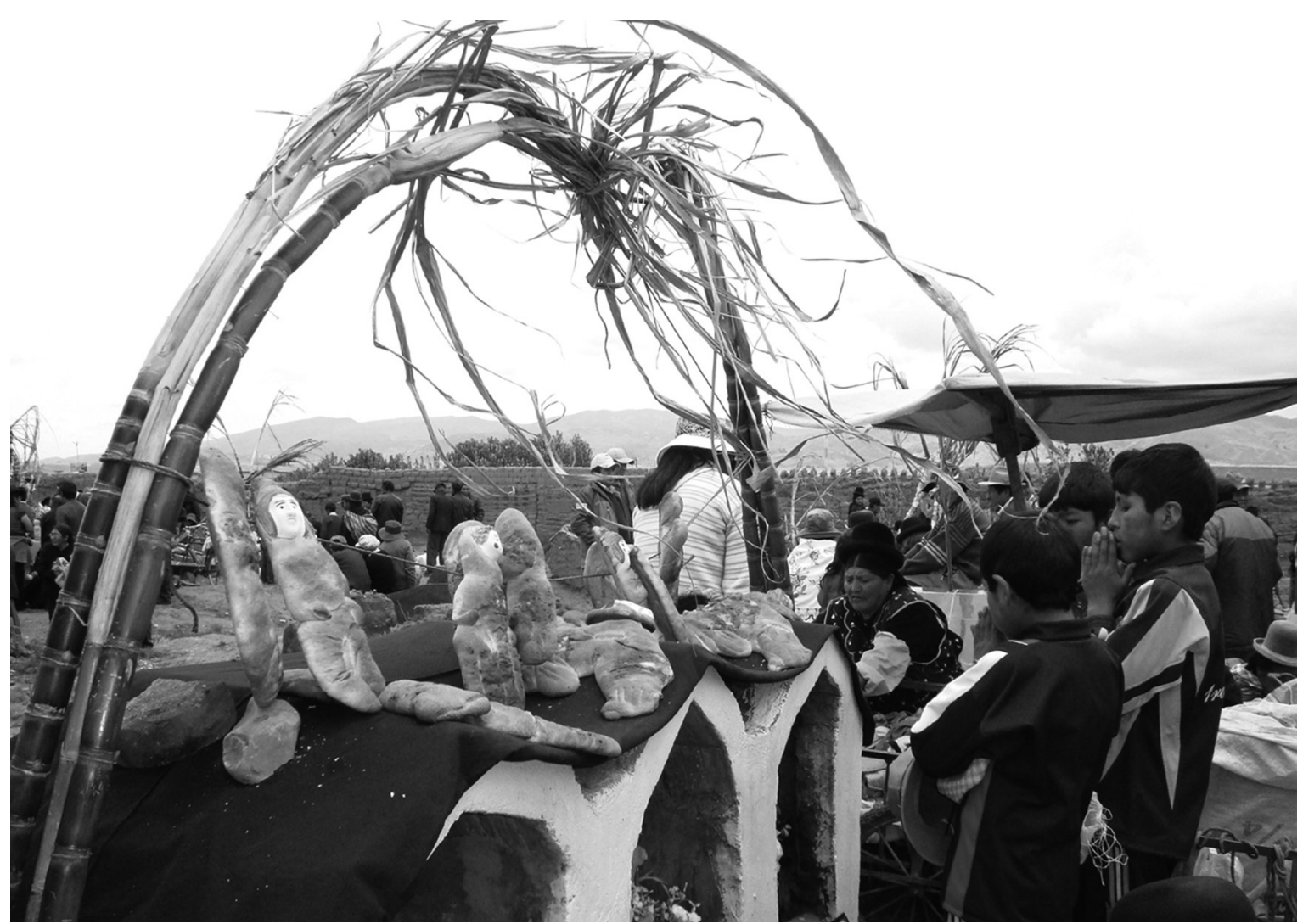

Figuras 14 y 15. Oración a través del arco durante el día de difuntos en el cementerio de Tiwanaku y en el rewe durante el lepün de Tringlo. 


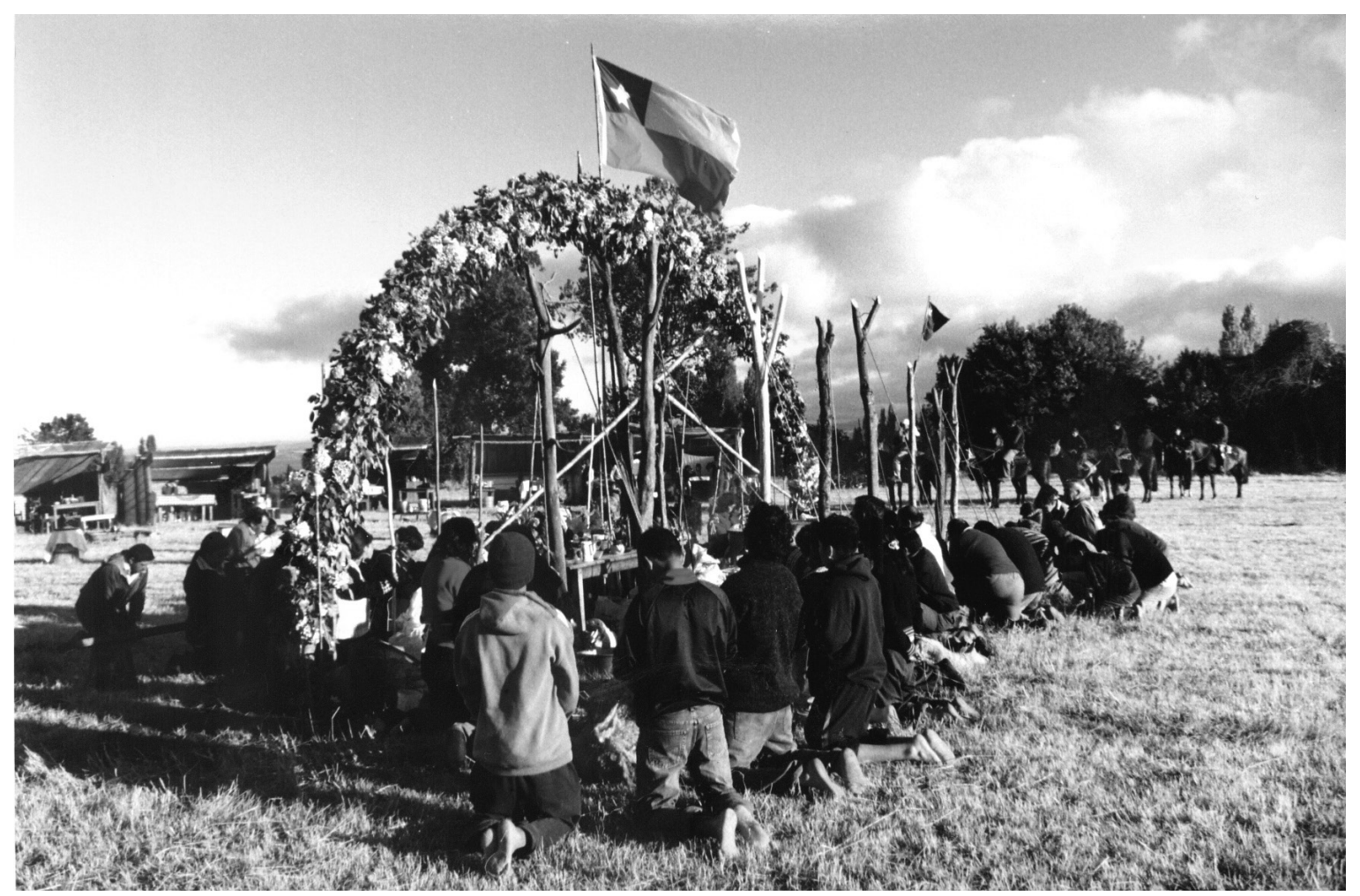

cierra el día dos de noviembre, cuando se llevarán los arcos y devolverán las cruces al cementerio, para despedir a las almas difuntas. Si bien el núcleo del simbolismo ritual se centra, en ambos casos, en la conexión con el mundo de arriba, el análisis del proceso ritual muestra el compromiso del mundo subterráneo o de abajo, articulado con el anterior. En este último es donde, respectivamente, se sitúa la casa de los espíritus tutelares o reposan los cuerpos de los muertos. El proceso ritual conecta los diversos planos del universo, el nodo simbólico del arco es el mediador entre ellos.

En términos figurativos, el arco aparece con referentes disímiles (arcoíris y Vía Láctea) pero con similares funciones, representando alternativamente un camino al cielo y un río por el que viajan las almas. En el caso williche, la complementariedad de este dualismo simbólico se manifiesta en la combinación de los motivos del arcoíris (arco diurno) y la Cruz del Sur, que metonímicamente refiere al arco nocturno. Esta sintaxis simbólica se encuentra en las pinturas rupestres del sitio Peumayén 2 de Río Manso y se muestra vigente en el rewe del lepün de la comunidad de Maihue, en Carimallín. Coincidentemente, en mapudun- gun el término que designa a la Vía Láctea es Wenu Leufu, lo que significa "río de arriba". En la cultura mapuche, los ríos son una vía por la que navegan las almas en su viaje a la otra vida en la Kilche Mapu (tierra de las entrañas), pero que también se proyectan en el cielo y permiten a los espíritus alcanzar el Wenu Mapu.

Algunas de las formas simbólicas aquí referidas son arquetípicas, otras presentan un sentido indexal y resultan, por lo mismo, igualmente recurrentes en otros contextos sociales (Carlson 1982). No obstante, el correlato de las etnopoéticas del arco muestra una textura cultural que no se explica en forma natural. Advertimos aquí una recurrencia en los nodos simbólicos articulados por la figura del umbral, donde se expresan metamodelos compartidos del universo. Lo relevante en este caso es el correlato de tramas simbólicas, que actualiza los paradigmas cosmovisionarios concordantes y produce una lógica ritual cotradicional.

\section{Detrás del umbral}

A modo de corolario, se puede señalar que el simbolismo 
del arco muestra profundidad histórica y continuidad en las culturas originarias del área andina. En el territorio mapuche williche, este se encuentra registrado en el arte rupestre del sitio Peumayén 2 con un rango de temporalidad estimada contextualmente entre los años 700 y 1200 DC, que lo sitúa en el período preincaico. Los datos etnográficos provenientes de los contextos mapuche williche, atacameño y aymara, los antecedentes etnohistóricos del mundo inca y las recurrencias iconográficas de las culturas centrales andinas del período Intermedio muestran al arco como un operador simbólico. Sus rasgos figurativos, constantes contextuales y usos rituales lo describen como un portal, cuyo umbral señala los límites espaciales y temporales y representa la comunicación entre diversos niveles del universo a los que este pone en relación. En los distintos casos analizados, el arco es un símbolo de trascendencia y conexión que permite la transitividad a través de estas dimensiones, y la integración o encuentro entre las entidades que las habitan. Si bien no se trata de un motivo presente en todos los desarrollos culturales del área, su recurrencia y grado de difusión lo perfilan como un símbolo panandino. En torno a él constatamos una serie de patrones cotradicionales, es decir, una constelación de rasgos culturales compartidos a partir de los cuales se puede inferir la existencia de relaciones interculturales entre los pueblos originarios del área andina. El sistema de trasformación de sus representaciones expone una matriz ideológica común que aquí intentamos explicitar. Sus evidencias, asociadas a distintos pulsos culturales (preincaicos e incaicos), son compatibles con la tesis de la circulación de recursos y rasgos simbólicos en diversos marcos temporales, pero su origen $y / o$ desarrollo histórico es un problema por resolver.
Agradecimientos Al Fondo Nacional de Ciencia y Tecnología (FONDECYT) que ha hecho posible nuestra investigación a través del proyecto 1120139: "La impronta andina en el sistema religioso cosmovisionario mapuche williche". A la Dirección de Investigación y Desarrollo de la Universidad Austral (DID), por su apoyo a través del proyecto DIS S 2012-2: "La alimentación de las almas, la muerte y las transformaciones del espíritu en el espacio centro y sur andino". En Trujillo, a Santiago Uceda por ayudarnos a comprender el simbolismo del arco en el mundo moche. En Puno, a Edmundo de la Vega, Héctor Velásquez, Vicente Alanoca y Víctor Ochoa, por aproximarnos a las concepciones del "arku" entre los aymara. En San Pedro de Atacama, a Ana María Lemus, Jimena Cruz y Leonor Mamani por su generosidad al compartir el conocimiento de los habitantes de Atacama y facilitarnos imágenes de arcos; a las familias atacameñas, que nos han permitido compartir en torno a sus mesas de difuntos. En Buenos Aires, a Mercedes Podestá por compartirnos sus impresiones sobre el arco en el arte rupestre del paralelo 42 y por orientarnos para acceder al sitio Peumayén 2. En Cusco, al Museo Inca gestionado por la Universidad Nacional San Antonio Abad, por permitirnos fotografiar piezas de su patrimonio arqueológico. En Lago Ranco y Río Bueno, a los miembros de las comunidades mapuche williche y sus espíritus tutelares por permitirnos compartir alimentos y conocimientos en torno al arco. A Nelson Rodríguez, por facilitarnos la fotografía del funeral de don Leonardo Cuante Loncoman. A Pablo Espinoza Concha, por cedernos la fotografía del día de muertos en Tiwanaku y su ayuda en la revisión de este texto. A los evaluadores anónimos, cuyas observaciones han contribuido a precisar, corregir y enriquecer nuestro trabajo.

\section{$*$ Referencias citadas}

ACOSTA, J. 1894. Historia natural y moral de las indias. Tomo II. Ramón Ángeles impresor, Madrid.

ADÁN, L., R. MERA, M. BECERRA y M. GODOY. 2004. Ocupación arcaica de territorios boscosos y lacustres de la región precordillerana andina del centro-sur de Chile. El sitio Marifilo-1 de la Comunidad de Pocura. Chungara. Revista de antropología chilena 36 , especial 2: 1121-1136.

ALONQUEO, M. 1979. Instituciones religiosas del pueblo mapuche. Ediciones Nueva Universidad, Santiago de Chile.
AUGUSTA, F. 1916. Diccionario araucano-español y español-araucano: Tomo primero. Imprenta Universitaria, Santiago de Chile.

AUSTIN, J. 1998. Cómo hacer cosas con las palabras. Paidós, Barcelona.

BACIGALUPO, M. 2007. Shamans of the foye tree. Gender, power, and healing among Chilean Mapuche. University of Texas Press, Austin.

BARROS ARANA, D. 1884. Historia jeneral de Chile: Tomo primero. Rafael Jover Editor, Santiago de Chile. 
BARTHES, R. 1972. Elementos de semiología. En La semiología, R. Barthes, C. Bremond, T. Todorov y Ch. Metz (Eds.), pp.15-71. Editorial Tiempo Contemporáneo, Buenos Aires.

BOUYSSE-CASSAGNE, T. 1988. Lluvias y cenizas. Dos pachacuti en la historia. Hisbol, La Paz.

BOYER, P. 1994. The naturalness of religious ideas. A cognitive theory of religion. University of California Press, Berkeley.

CÁCERES, E. 2002. El juicio del agua. Abya-Yala, Quito.

CARLSON, J. 1982. The double-headed dragon and the sky: A pervasive cosmological symbol. Annals of New York Academy of Sciences 385: 135-163.

CARRIÓN, R. 2005. La religión en el antiguo Perú. Instituto Nacional de Cultura, Lima.

CERECEDA, V. 1988. Aproximaciones a una estética andina: de la belleza al tinku. En Raíces de América. El mundo aymara, X. Albó (Comp.), pp.283-364. Alianza Editorial, Madrid.

CERVANTES, S., C. GARRIDO y S. SANTANDER. 2008. Tras los pasos del torito. Imprenta Ercilla, Antofagasta.

CORNEJO, L. 2014. Sobre la cronología del inicio de la imposición cuzqueña en Chile. Estudios Atacameños 47: 101-116.

CRUZ, J., J. CORTÉS y C. YUFLA. El universo de nuestros abuelos. Proyecto de investigación etnoastronómico de Atacama. IIAM \& ALMA. San Pedro de Atacama. Ms.

DAMEN, F. 1996. La fiesta de la pasión en Obrajes. Abya-Yala, Quito.

DELGADO, F. 2002. Estrategias de autodesarrollo y gestión sostenible en el territorio en ecosistemas de montaña. Complementariedad ecosimbiótica en el ayllu Majasaya Mujlli, Departamento de Cochabamba, Bolivia. Plural \& Agruco, La Paz.

DILlEHAY, T. 1990. Araucanía: Presente y pasado. Andrés Bello, Santiago de Chile.

1998a. Mi Experiencia de aprendizaje en Chile me enseñó más antropología de lo que las aulas jamás me enseñaron. Entrevistado por Rolf Foerster, Ximena Navarro y Lautaro Núñez. Revista Austral de Ciencias Sociales 2: 37-46.

1998b. Felines, patronyms, and history of Araucanians in the southern Andes. En Icons of Power: Feline Symbolism in the Americas, N. Saunders (Ed.), pp. 203-227. Routlegde, Londres.
2004. Monteverde: un asentamiento humano del pleistoceno tardio en el sur de Chile. LOM, Santiago de Chile.

2011. Monumentos, imperios y resistencia en los Andes. Ocho Libros, Qillqa y Vanderbilt University, Santiago de Chile.

ECO, U. 1980. Tratado de semiótica general. Lumen, Barcelona.

FERNÁNDEZ, G. 2006. Apaxatas de difuntos en el altiplano aymara de Bolivia. Revista Española de Antropología Americana 36: 163-180.

FLURY, L. 1944. Guiliches. Imprenta de la Universidad Córdoba, Córdoba.

GARCÍA ESCUDERO, M. 2007. El arcoíris en la cosmovisión prehispánica centroandina. Gaceta de Antropología 23: artículo 15.

GARCILASO DE LA VEGA, I. 2012. Comentarios reales de los incas. Ediciones El Lector, Arequipa.

GARRIDO, C. 1999. El hervor de la vida contenido en la vida de ancianos atacameños. Tesis de Licenciatura en Antropología. Universidad Austral de Chile, Valdivia.

2007. Caminos cruzados hacia el imaginario colla. Tesis de Magister en Antropología. Universidad Católica del Norte, San Pedro de Atacama.

GARRIDO, C. y A. M. LEMUS. 2013. Fiesta patronal de Pachica: 'Viva San José.' Gisoc Consultores, Calama.

2013. Fiesta patronal de Esquiña: 'Viva San Pedro'. Gisoc Consultores, Calama.

GISBERT, T. 2008. El paraíso de los pájaros parlantes. Plural, La Paz.

GOLTE, J. 2009. Moche. Cosmología y sociedad. Instituto de Estudios Peruanos \& Centro Bartolomé de las Casas, Lima.

GREBE, M. 1986. Algunos paralelismos en los sistemas de creencia mapuche: los espíritus del agua y la montaña. Cultura, Hombre y Sociedad 3(2): 143-154.

1995-1996. Continuidad y cambio en las representaciones icónicas: significados simbólicos en el mundo sur andino. Revista Chilena de Antropología 13: 137-154.

1996. Patrones de continuidad en el mundo sur-andino: creencias y cultos vinculados a los astros y los espíritus de la naturaleza. En Cosmovisión Andina: expresión y sentimiento espiritual andino-amazónico, pp. 205-220. Centro de Cultura, Arquitectura y Arte Taipinquiri, La Paz. 


\section{Rodrigo Moulian y Cristina Garrido}

2002. Los mapuche en el contexto del mundo andino: algunas perspectivas interculturales. Lengua y Literatura Mapuche 10: 23-34.

GREBE, M., S. PACHECO y J. SEGURA. 1972. Cosmovisión mapuche. Cuadernos de la Realidad Nacional 14: 43-73.

GREBE, M. y B. HIDALGO. 1988. Simbolismo atacameño: un aporte etnológico a la comprensión de significados culturales. Revista Chilena de Antropología 7: 75-97.

GUAMÁN POMA DE AYALA, F. 1980. Nueva coronica y buen gobierno. Biblioteca Ayacucho, Caracas.

GUEVARA, T. 1911. Folklore araucano. Imprenta Cervantes, Santiago de Chile.

IZKO, J., R. MOLINA y R. PEREIRA. 1986. Tiempo de vida y muerte. Estudio de caso en dos contextos andinos de Bolivia. Consejo Nacional de Población \& Centro Internacional de Investigación para el Desarrollo, La Paz.

JUNG, C. 1994. Arquetipos e inconsciente colectivo. Paidós, Barcelona.

KESSEL, J. 1982. Danzas y estructuras sociales de Los Andes. Instituto de Pastoral Andina, Cusco.

LATCHAM, R. 1924. Organización social y creencias religiosas de los antiguos araucanos. Imprenta Cervantes, Santiago de Chile.

LÉVI-STRAUSS, C. 1984. El pensamiento salvaje. Fondo de Cultura Económica. México.

1986. Mitológicas I. Lo crudo y lo cocido. Fondo de Cultura Económica, México.

1997. Mitológicas IV. El hombre desnudo. Siglo XXI. México.

LIRA, J. y M. MEJÍA. 2008. Diccionario quechua castellano, castellano quechua. Universidad Ricardo Palma, Lima.

LÓPEZ BARALT, M. 1986. The yana k'uychi or black rainbow in atawallpa's elegy: a look at andean metaphor of liminality in cultural context. En Myth and imaginary in the new world, E. Magaña y P. Mason (Eds.), pp. 261-303. Centro de Estudios y Documentación Latinoamericanos, Amsterdam.

LUMBRERAS, L. 1968-1969. El área cotradicional meridional andina. Boletín del Museo Nacional de Historia Natural 30: 65-79.

1981. Arqueología de la América andina. Editorial Milla Batres, Lima.

MAKOWSKI, K. 1996. Seres radiantes, el águila y el búho. La imagen de la divinidad en la cultura mochica (siglos II-VII D.C.). En Imágenes y Mitos, K. Makowski, I. Amaro y M. Hernández (Eds.), pp. 13-114. Australis, Lima.

2000. Las Divinidades en la iconografía mochica. En Los dioses en el antiguo Perú. Banco de Crédito del Perú, Lima.

MARTY, R. 1997. 76 definitions of the signs by C. S. Peirce. En Arisbe: The Peirce Gateway, J. Randell (Ed.). http://www.iupui. edu/ arisbe/rsources/76DEFS/76defs.HTM.

MORRIS, C. 1985 . Fundamentos de la teoría de los signos. Paidós, Barcelona.

MOTTA, E. 1985. De morenos y cruceros. Religiosidad popular, intercambio y cosmovisión andina. Universidad Nacional Mayor de San Marcos, Lima.

2011. Pacha: visión andina del espacio tiempo en perspectiva del pensamiento seminal. Tesis Doctoral. Universidad Nacional Mayor de San Marcos, Lima.

MOULIAN, R. 2005. Tiempo de lepün. Universidad Austral de Chile \& Programa Orígenes, Valdivia.

2008. Ngen rupu/El camino del Ngen. Universidad Austral de Chile \& Consejo Nacional de la Cultura y las Artes, Valdivia.

2012. Metamorfosis ritual: desde el ngillatun al culto pentecostal. Kultrun \& Universidad Austral de Chile, Valdivia.

MOULIAN, R. y C. VALDÉS. 2001. Abuelito Huenteao, mito y ritual. Consejo Nacional de la Cultura y las Artes \& Universidad Austral de Chile, Valdivia.

MOULIAN, R. y M. CATRILEO. 2013. Kamaska, kamarricun y müchulla. Préstamos lingüísticos y encrucijadas de sentido en el espacio centro y sur andino. Alpha 37: 249-263.

MOULIAN, R. y P. ESPINOZA. 2014. Pneumatología, paisaje y culto. Patrones andinos en los procesos de ancestralización de la cultura mapuche emplazados en la naturaleza. Chungara. Revista de antropología chilena 46(4): 637-650.

MURÚA, M. 2001. Historia general del Perú. Dastín, Madrid.

ODENGARDO, P. 1990. El mundo de los incas. Editorial Historia 16, Madrid.

ORTMANN, D. 2002. Ciencias de la religión en el Perú. Fondo Editorial Universidad Nacional Mayor de San Marcos, Lima.

OTTO, R. 2001. Lo santo. Lo racional y lo irracional en la idea de Dios. Alianza Editorial, Madrid. 
PARMENTIER, R. 1994. Signs in society. Studies in semiotic anthropology. Indiana University Press, Indiana.

PEIRCE, C. 1965. Collected Papers of Charles Sander Peirce. Vol. 1 y 2. The Belknap Press of Harvard University Press, Cambridge.

1974. La ciencia de la semiótica. Ediciones Nueva Visión, Buenos Aires.

PIKE, K. 1976. Puntos de vista éticos y émicos para la descripción de la conducta. En Comunicación y cultura. Volumen 1, La Teoría de la Comunicación Humana, A. Smith (Comp.), pp. 223-247. Ediciones Nueva Visión, Buenos Aires.

PREUCEL, R. y BAUER, A. 2001. Archaeological pragmatics. Norwegian Archaeological Review 34(2): 85-96.

PODESTÁ, M., A. M. AlbORNOZ, A. VASINI y E. TROPEA. 2009. El sitio Peumayén 2 en el contexto del arte rupestre del bosque andino patagónico. Comechingonia Virtual 3(2): 117-123.

ROSAT, A. 2009. Diccionario enciclopédico quechua-castellano del mundo andino. Editorial Verbo Divino, Cochabamba.

ROSSI, I. 1973. The unconscious in the anthropology of Claude LéviStrauss. American Anthropologist 75: 20-48.

SÁNCHEZ GARRAFA, R. 2013. Simbolismo y ritualidad en torno a la papa en los Andes. Runa Yachachiy: http://alberdi.de/MitPaSaGaI13.pdf.

SÁNCHEZ GARRAFA, R. 2012. Representación monumental de cosmos en murales mochica. En Cosmos Moche, R. Ochoa Berteaga (Ed), pp.23-80. Museo Andrés del Castillo, Lima.

SANTA CRUZ PACHACUTI, J. 1995. Relación de antigüedades de este reino del Perú. Fondo de Cultura Económica, Lima.
SAUSSURE, F. 1986. Curso de lingüística general. Losada, Buenos Aires.

STEELE, P. y C. ALLEN. 2004. Handbook of inca mythology. Abc-Clío, Santa Barbara.

TAYLOR, G. 2000. Camac, camay, camasca y otros ensayos sobre Huarochiri y Yauyos. Centro de Estudios Regionales Andinos Bartolomé de Las Casas, Instituto Francés de Estudios Andinos, Lima. 2001. Huarochiri. Ritosy tradiciones. IFEA y Lluvia Editores, Lima.

TURNER, V. 1999. La selva de los símbolos. Siglo XXI, Madrid.

UCEDA, S. 2004a. Los sacerdotes del arco bicéfalo: tumbas y ajuares hallados en la Huaca de la Luna y su relación con rituales moche: Primera parte. Revista de Arquitectura, Diseño y Construcción 98: 96103.

2004b. Los sacerdotes del arco bicéfalo: tumbas y ajuares hallados en la Huaca de la Luna y su relación con rituales moche: Segunda parte. Revista de Arquitectura, Diseño y Construcción 99: 9299.

2008. The priests of bicephalus arc. Tombs and effigies found in Huaca de la Luna and their relation to Moche rituals. En The art and archeology of the moche, S. Bourget and K. Jones (Eds), pp.153178. University of Texas Press, Austin.

ULFE, M. E. 1997. Un ritual de matrimonio en Andahuaylas. Anthropologica 15: 289-303.

VALKO, M. 2005. Imágenes, signos e imaginarios de la degollación que no fue. En GIS Réseau Amérique latine. Actes du 1er Congrès du GIS Amérique latine: Discours et pratiques de pouvoirs en Amérique latine, de la période précolombienne à nos jour. http://hal.archives-ouvertes.fr/ docs/oo/15/16/82/PDF/VALKO_Marcelo_L_GIS_2005. pdf. Consultado 13 mayo 2014 . 